DIGITAL COMMONS
$@$ UNIVERSITY OF SOUTH FLORIDA

Volume 7

Issue 1 Volume 7.1 (Spring 2017)

\section{ABO: Interactive Journal for Women in the Arts, 1640-1830}

2017

\title{
Arabella's Valentines and Literary Connections [dot] com: Playing with Eighteenth-Century Gender Online
}

\author{
Melanie D. Holm \\ Indiana University of Pennsylvania, holm.melanie@gmail.com
}

Follow this and additional works at: https://digitalcommons.usf.edu/abo

Part of the Dramatic Literature, Criticism and Theory Commons, Educational Methods Commons, Literature in English, British Isles Commons, and the Women's Studies Commons

\section{Recommended Citation}

Holm, Melanie D. (2017) "Arabella's Valentines and Literary Connections [dot] com: Playing with Eighteenth-Century Gender Online," ABO: Interactive Journal for Women in the Arts, 1640-1830: Vol.7: Iss.1, Article 5. http://doi.org/10.5038/2157-7129.7.1.1138

Available at: https://digitalcommons.usf.edu/abo/vol7/iss1/5

This Pedagogy is brought to you for free and open access by Digital Commons @ University of South Florida. It has been accepted for inclusion in ABO: Interactive Journal for Women in the Arts, 1640-1830 by an authorized administrator of Digital Commons @ University of South Florida. For more information, please contact digitalcommons@usf.edu. 


\title{
Arabella's Valentines and Literary Connections [dot] com: Playing with Eighteenth-Century Gender Online
}

\begin{abstract}
This article describes two digital assignments that ask students to imaginatively embody characters from eighteenth-century texts written by women in order to cultivate a greater awareness of the critical role of gender and gender critique in these works. The first of these assignments, "Arabella's Valentines," asks students to translate dialogue from Charlotte Lennox's The Female Quixote as humorous Internet memes. The second assignment, "Literary Connections [dot] com," asks students to imagine how characters from the course archive might represent themselves on an internet dating site. Through creative role-play facilitated by these digital genres, students engage with the texts in stimulating and playful ways that extends their consideration of writers' works beyond the page. In the article I explain how these activities were deployed using PowerPoint and Tumblr, and for the second assignment, Google Forms, with step-bystep instructions for replicating the technological aspects of the assignments, and add reflections on the outcome of these assignments for student learning.
\end{abstract}

\section{Keywords}

digital, tumblr, pedagogy, lennox, quixotism, quixote, gender, women's writing, online assignments, social media

\section{Creative Commons License}

(c) $($ ) $\ominus$

This work is licensed under a Creative Commons Attribution-No Derivative Works 3.0 License. 


\title{
Introduction to $A B O$ 's Teaching Forum
}

\author{
Cynthia Richards, Pedagogy Editor
}

This issue inaugurates the first of $A B O$ 's Teaching Forums. These forums feature a series of shorter essays that are in conversation with one another about issues related to teaching all aspects of women in the arts in the long eighteenth century. Geared to a scholarly audience, these forums may be both practical and theoretical in nature, but will uniformly take as their focus the public work of the classroom and how scholarship is translated into action. These first four essays illustrate that focus by foregrounding practices in which students are asked-sometimes quite literally - to embody knowledge of the eighteenth century, and particularly, how gender reframes that experience. As such, they speak to the long-standing feminist practice that acknowledges the role of the body in shaping experience and point to emerging insights in Body Studies, which focus on a history of the body and its representation.

Listed chronologically in terms of content, the four essays included in the forum are: "Arabella's Valentines and Literary Connections [dot] com: Playing with Eighteenth-century Gender Online" by Melanie Holm; "Less of the Heroine than the Woman': Parsing Gender in the British Novel" by Susan Carlile; "Embodying Gender and Class in Public Spaces through an Active Learning Activity: Out and About in the Eighteenth Century" by Ann Campbell; and "Embodying Character, Adapting communication; or, the Senses and Sensibilities of Epistolarity and New Media in the Classroom" by Jodi L. Wyett.

\section{Arabella's Valentines and LiteraryConnections.com: Playing with Eighteenth-Century Gender Online}

One of the greatest difficulties I faced in my 200-level literature course "Novel Women: Women Writers 1660-1900" was how to increase the sensitivity of my twenty-first century students to the often subtle dynamics of gender critique in eighteenth-century literary texts. In her article, "Embodying Character, Adapting Communication: Text Tweet, Write Exercise," Jodi Wyett reflects on this issue in the context of reading Jane Austen's Sense and Sensibility, observing that it "can be challenging to students for whom eighteenth-century gendered social contexts and generic conventions clash with modern social codes and generic expectations based on film ... and social media." When asked to read with an alertness to gender criticism, the challenge students face is doubled: they must understand the historical contexts of relationships between the sexes as well as the sophisticated literary techniques authors employ in their critiques. A student in a non-major, 200-level literature course is likely familiar with neither. Very early in my course, students 
understandably expressed a high degree of frustration with both the readings and the critical questions they were asked to apply to them. The course archive included Aphra Behn's The Rover, Mary Davys's The Reformed Coquette, Eliza Haywood's Fantomina, Charlotte Lennox's The Female Quixote, Mary Hays's A Victim of Prejudice, Jane Austen's Sense and Sensibility, and Charlotte Brontë's Jane Eyre. Students diligently kept up with the pace of reading one volume of a novel per class meeting, but did so as an exercise in deciphering words on the page and noting plot points: there was little critical awareness, and even less pleasure. The problem, as many of my students so succinctly put it: "I just can't get into it."

How do we get students "into" the historically distant and formally challenging works that are at the heart of eighteenth-century studies? And how can we close that distance so that authors' critical voices and conversations about issues like gender oppression become recognizable to twenty-first century students? While brief lectures and supplementary materials would do some of this work, these questions led me to consider the ways in which my students might already be comfortable thinking about issues of gender as well as the critical mediums and social contexts that were familiar to them. With Marc Prensky's presentation of contemporary students as "Digital Natives" in mind, I considered the digital ontology of students' lived gender experience and identified familiar digital genres and spaces in which gender was visibly embedded: social media memes and online dating profiles. In turn, I attempted to create two sequential assignments of digitalmediated literary embodiment in order to help students identify and deploy eighteenth-century gender criticism.

In this essay I will describe the two assignments I developed and assigned for this course: "Arabella's Valentines," a collection of anti-Valentine's Day memes, and "LiteraryConnections.com," an online dating site for literary characters. The goal of these assignments was to help my students to "get into" the texts by asking them to "get into" the characters in playful digital domains. These assignments asked students to inquire into and adopt eighteenth-century language, mores, and literary devices by translating them into modern online venues of gendered communication, play, and interplay, using commonly available technologies and social media platforms to motivate student discovery of gendered attitudes. As with the assignments described by Wyett and by Ann Campbell in "Embodying Gender and Class in Public Spaces Through an Active Learning Activity: "Out and About in the Eighteenth Century," my assignments ask students to embody characters through creative role-playing. Across these two assignments, students mirrored the individual learning experience Wyett crafts and the group engagement Campbell creates. Similarly, "Arabella's Valentines" focuses on a single text as does Wyett's "Embodying Character," while "LiteraryConnections.com" addresses the entire course archive, as does Campbell's "Out and About." Either of my activities, however, could be scaled up or down 
based on need, and could either require individual or group participation. Alongside assignment descriptions, I include links to the students' projects, the original assignment descriptions, and "how-to" documents that are intended to demystify the steps required to adopt and adapt these assignments for different courses and texts.

\section{1. “Arabella's Valentines"}

"Arabella's Valentines" asked students to focus on the language play of the main character of Charlotte Lennox's The Female Quixote, Arabella. The objective of this exercise was to facilitate recognition of Lennox's use of Romance ideology to expose the commodity status of women in the eighteenth-century marriage market. Students were asked to isolate textual moments in which Arabella refuses and resists courtship and marriage proposals, and then select those which seemed to depart most sharply from the male interlocutor's expectations. By looking for what seemed like moments of subversion or dissonance, I hoped that students would gain greater understanding of the structures the author seeks to subvert. Lennox's satiric indirection, I found, when broken down into individual phrases, suggestively approximates the critical methodology of internet memes. I therefore challenged my students to create candy-heart memes out of these subversive moments with the hope that they would learn to laugh with Lennox by using her words to provoke critical laughter in others.

Wyett's project powerfully illustrates how medium affects communication by asking students to communicate from the perspective of one character across

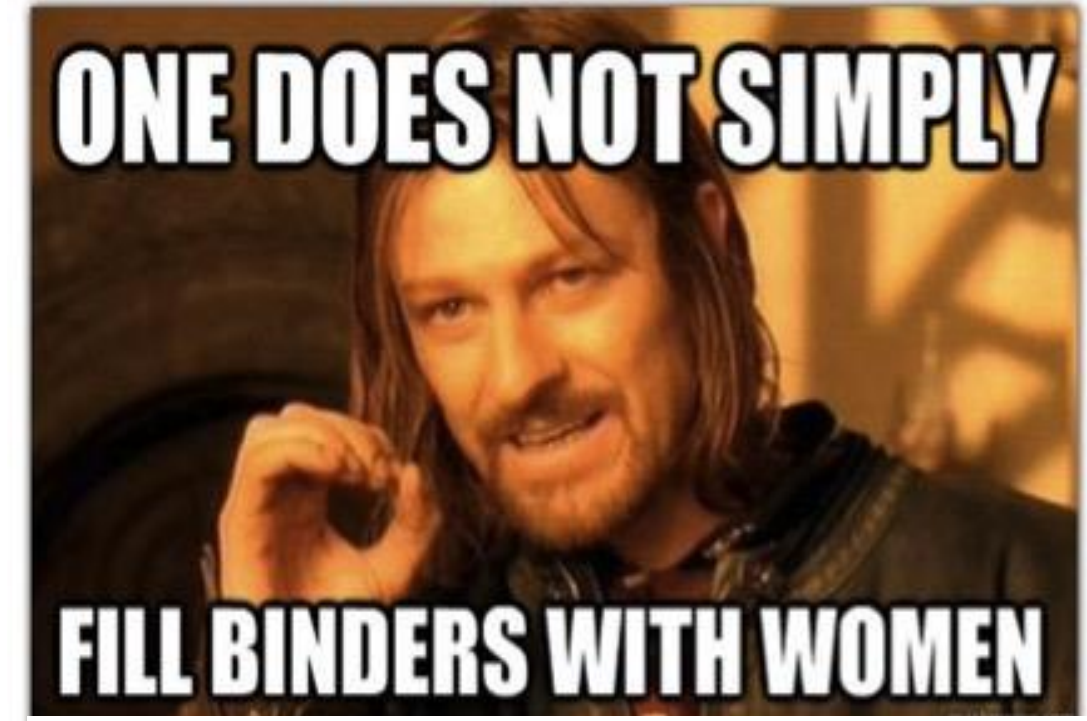

Figure 1 
four physically different modes of writing. In my assignment planning, I was especially interested in how isolating and deploying dialogue from a novel in a digital medium could enable students to unlock its subversive potential. My students were generally familiar with the single image/text format of memes, the most notable of that period being perhaps Mitt Romney's "Binders Full of Women" and the actor Sean Bean as Boramir from The Lord of the Rings suggesting that "One does not simply...," which happily intersected in the very memorable and popular meme "One does not simply fill binders with women"

[Figure 1].

A similarly popular meme series with a feminist bent today would be the "Hey Girl!" memes featuring Ryan Gosling [Figure 2].

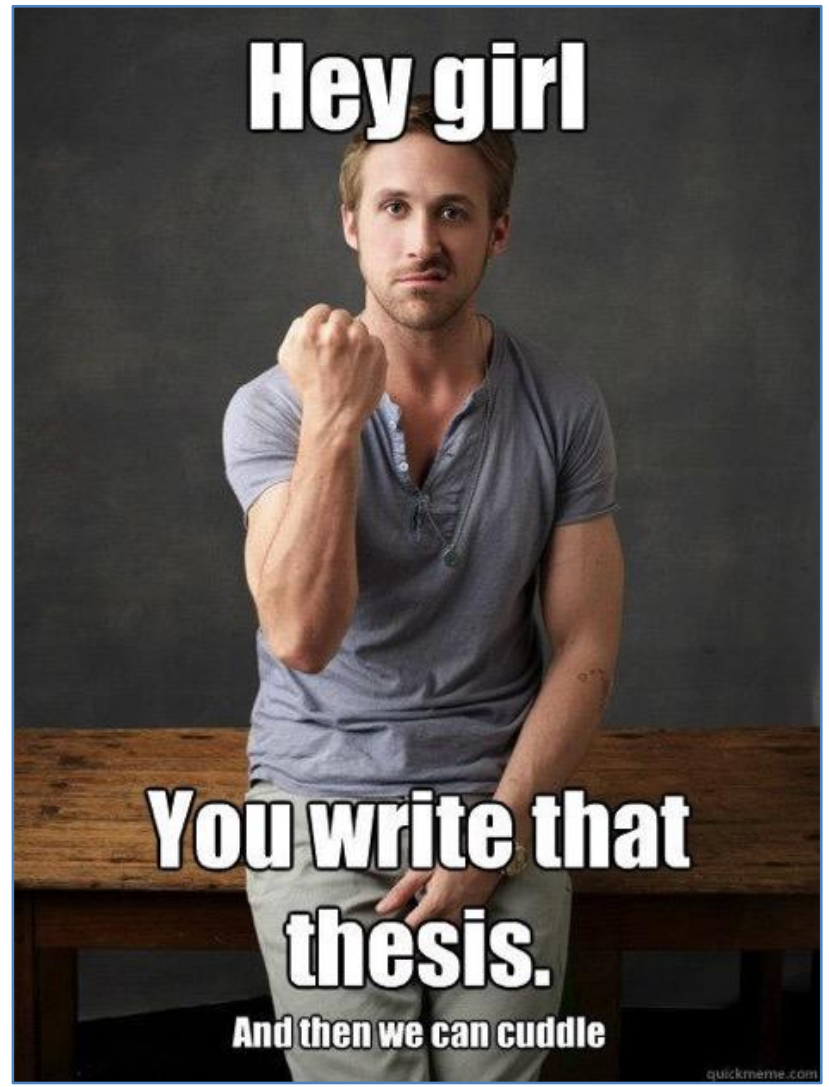

Figure 2: Example Meme

The timing of the assignment fell shortly before Valentine's Day, which made for a seasonally serendipitous possibility of co-opting the familiar imagery of candy hearts with romantic homilies impressed upon them. The assignment, which 
follows, took full advantage of the medium and moment to create the class project website: www.quixoticValentines.tumblr.com.

\section{1: The assignment}

Students were required to identify three episodes in the text in which Arabella refuses or refutes the advances of suitors or otherwise complains from her Romance pedestal about male conduct. They then had to post their choices to a course wiki and tweet them, thereby minimizing duplicates among classmates. Students then had to download and insert the text and page number into a PowerPoint template I had previously designed, and then upload their work to a course Tumblr.

I gave students a motivating example [Figure 3] to help them understand where the assignment was going and the spirit of participation I was after.

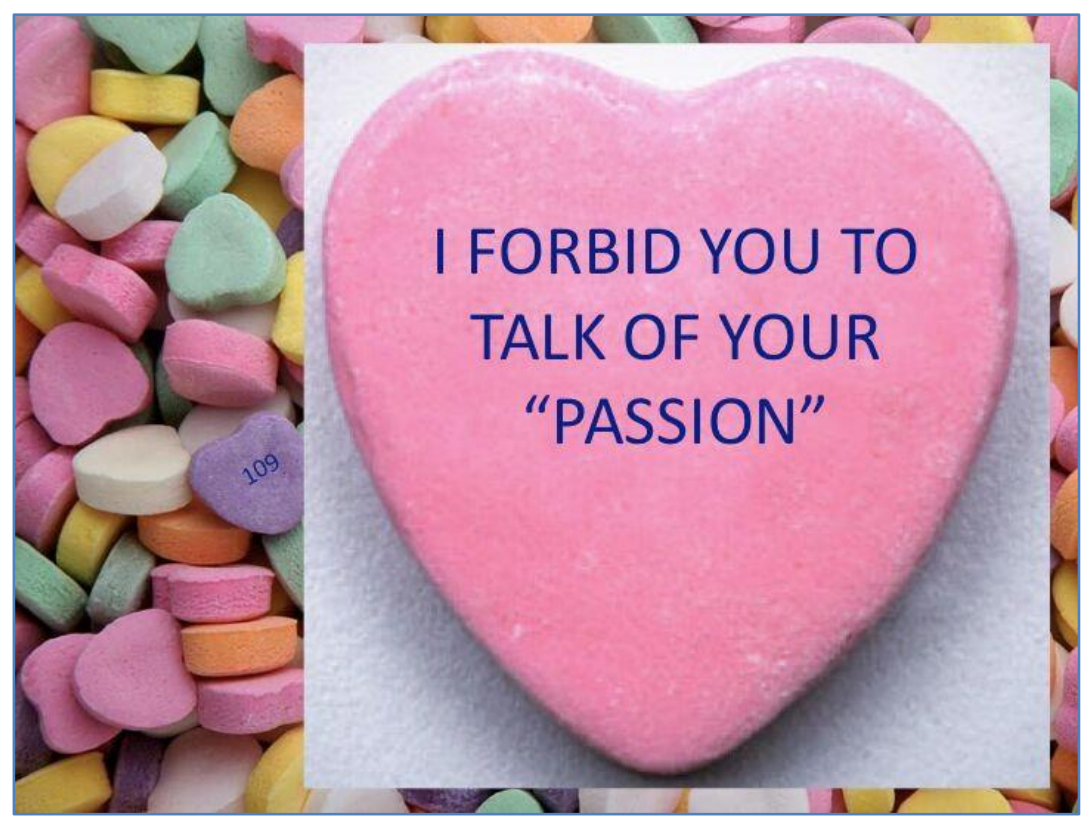

Figure 3: Example Shown to Class

You can read the full assignment description in Appendix A and the step-by-step instructions on how to replicate it using PowerPoint and Tumblr in Appendix B. Controlling for repetition, the class created thirty-six different quixotic-valentine hearts [Figure 4], which are still on display at QuixoticValentines.tumblr.com. 


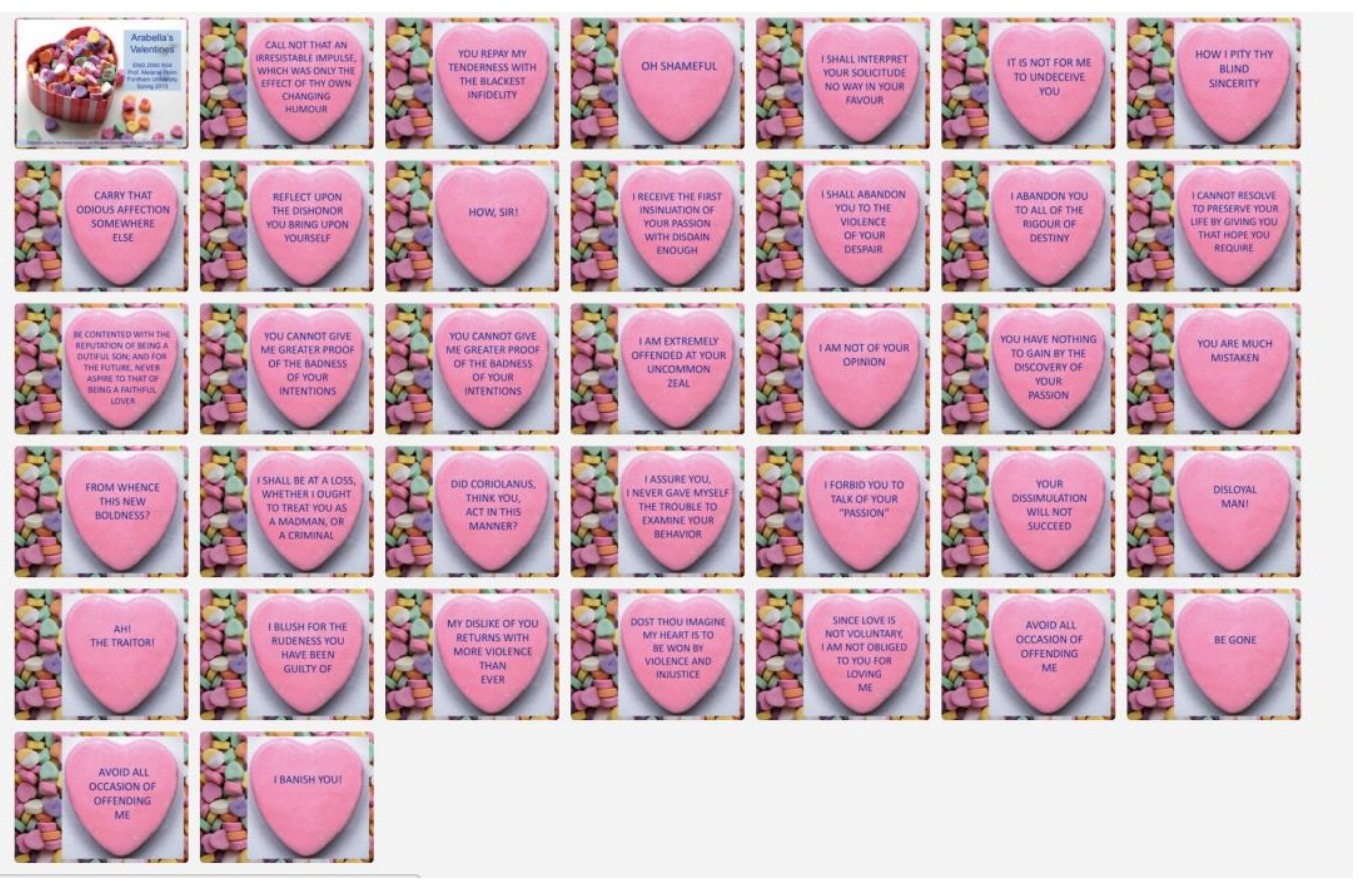

Figure 4: Archive of Arabella's Valentine Hearts

\subsection{Class discussion}

When class began on Valentine's Day, we looked through the hearts together and amid much laughter, students were tasked with explaining the critical logic behind their selections and what these phrases told us about the cultural expectations for women. I admire how Susan Carlile, in "'Less of the Heroine than the Woman': Parsing Gender in the British Novel" asks students in her activity to interrogate the concept of "heroine" in different novels, and via those literary scaffolds, gain insight into cultural expectations for women by way of an ideal. In a less developed manner, my students examined each heart and its passage in detail as a class, and they then attempted a similar literary excavation of eighteenth-century expectations for women by pursuing the following questions: What prompted Arabella's remark? What was Arabella offended by? What did she expect or desire as an alternative? What does Lennox encourage us to notice in this interaction about the status of women? Giving students the creative task of translating Arabella's words into memes allowed students to embody her character and, in turn, consider the words on the page as not thick eighteenth-century prose to be waded through, but sharp comic critique of a forceful female wit. 
The reflective papers students produced in conjunction with their memes showed an enthusiastic application of close-reading skills and a clear appreciation for the irony and wit of the author, as well as anger at, if not merely understanding of the status of, women in the period. Our comical Valentine's Day enterprise tapped into feelings of profound frustration about the role of women in heterosexual relationships both then and now, ultimately providing an object lesson in the power of humor to persuade, critique, and enflame.

Perhaps the most enjoyable part of this assignment for students was that they were able to share their work with friends through Twitter and Facebook, the larger university community through the English Department's promotion of the project on their webpage, and the anonymous online public. The page was retweeted by people student didn't know, including English professors and academic publishers, which gave rise to further class discussions about public scholarship and the circulation of texts in the public sphere. This phenomenon of an anonymous audience elicited both excitement and vulnerability, particularly a concern that people would understand that the hearts were supposed to make people laugh about our own gender disparities and weren't just about an eighteenth-century book. From their ownership of the project in the face of an anonymous public came expression of a strong kinship with Lennox as author, and students thereafter were much more disposed to sympathize with other women writers on the syllabus. To my surprise, when presenting this assignment on the panel "Let's Get Engaged! Innovative Approaches to Teaching Gender in Eighteenth-Century Novels," chaired by Heather King Shamp at ASECS 2016, I discovered that two of my co-panelists had featured the Arabella Tumblr in in class discussion on The Female Quixote. This happy coincidence suggests to me that digital pedagogy of this kind can pay dividends beyond the immediate lesson by encouraging students to embody the roles of character, author, artist, and public scholar.

\section{2. "Literary Connections.com"}

My second assignment, LiteraryConnections.com, was built from the energy and affective momentum generated by "Arabella's Valentines" as well as the technological and literary skills students had learned. "LiteraryConnections.com" differs from "Arabella's Valentines" in a number of ways: it asks for a more sophisticated technological commitment, for students to consider a variety of characters from many novels, and for students to work in pairs (though it could be applied to one novel only and students could perform the work alone). It is a tool for discovering the dynamics of the eighteenth-century marriage market as represented and critiqued in eighteenth-century texts via parody: the parodies of something with which they were less familiar, the gendered dynamics of the marriage market in eighteenth-century text, through parody of internet dating sites, 
a cultural space with which they were all (and in some cases, all too) familiar. The goal of this assignment was to extend close-reading beyond the limits of dialogue and comparatively across the course archive by translating literary characters into our modern "marriage" marketplace. A secondary goal was to have students engage in creative character analysis with another person as a way of stimulating the thinking of each. Differences in how they read the same characters, what they noticed, and their own understanding of the role of gender in culture, both then and now, I gambled, would stimulate their thinking while also teaching them how to talk about literature effectively. This assignment is therefore a creative exercise in literary analysis and intellectual exchange.

\subsection{The assignment}

This assignment asked my students to embody characters by considering how Elinor Dashwood or Lord Rochester represent themselves as suitable matches for others in their native texts as well as what they are looking for in a significant other, and then imagining how they would fare in online dating. Students had to perform a more penetrating, sustained, and comparative application of close-reading in order to consider not just what characters said in a given text, but also their motives, actions, and values as represented in a given work. They also had to sit at a computer and fill out a dating profile as that character or on that character's behalf, an experience I thought would kinetically enhance their embodiment.

Working in pairs, students chose three characters from three different texts: one male lead, one female lead, and one minor character. They were required to then fill out an online dating form that I had created using Google Forms for each character, using what they could glean from the text in concert with their imaginations to do each character (poetic) justice. After completing this part of the assignment, each student had to write a short paper that explained the choices they made for representing characters in the profiles, justifying their responses to at least five significant profile questions (name and sex did not, for example, count as significant, while pick-up lines, profile names, and photograph selection, alongside questions like "five things I can't live without" could). You can read the full assignment in Appendix C.

The technological investment for this activity is more elaborate and involved than in the previous assignment, but requires no particular expertise and could be modified in a variety of ways to suit characters from a range of texts or an individual text. In addition to the PowerPoint and Tumblr work of "Arabella's Valentines," this assignment made use of Google Forms, a free technology that produces online form and stores the data entered into it in a personal database. I chose to create an online dating profile form so that I could provide students with a more or less true-to-life experience of visiting an online dating site, hypothesizing 
that their enjoyment in the activity would be heightened by getting to type in the information and submit it, as they might in real life. While I created the profile form, students could certainly participate in the form's production, and it is something I plan to try in the future. The information they put into the forms automatically went into a database. A student worker and I copied and pasted the information into a PowerPoint template and then uploaded to a Tumblr. Working together this took us about an hour for a class of 22. If time and help are not available, then the process from "Arabella's Valentine's" can be reproduced so that students enter their information directly into a template and upload it themselves into a Tumblr. The elaborate student-user experience is certainly not necessary for the assignment to function well, but enhances the role-playing mentality of the assignment.

What I liked about using Google Forms was that it allowed me to customize questions and possible responses in a way that respected our eighteenth-century idiom, but did so in a way that had a touch of the ridiculous and suggested the critical play in which students could indulge. For example, under the question "Kids," I added to the standard options "there are rumors of natural children, but they are lies" and "no, they are noisy" (a particular favorite for my Jane-ites). For the question "Age," I began with the conventional minimum of eighteenth-century female desirability, 15, and ended "on the wrong side of thirty-five" [Figure 5]. The full profile form can be found here. For step-by-step instruction on how to create the form, see the tutorial in Appendix D.

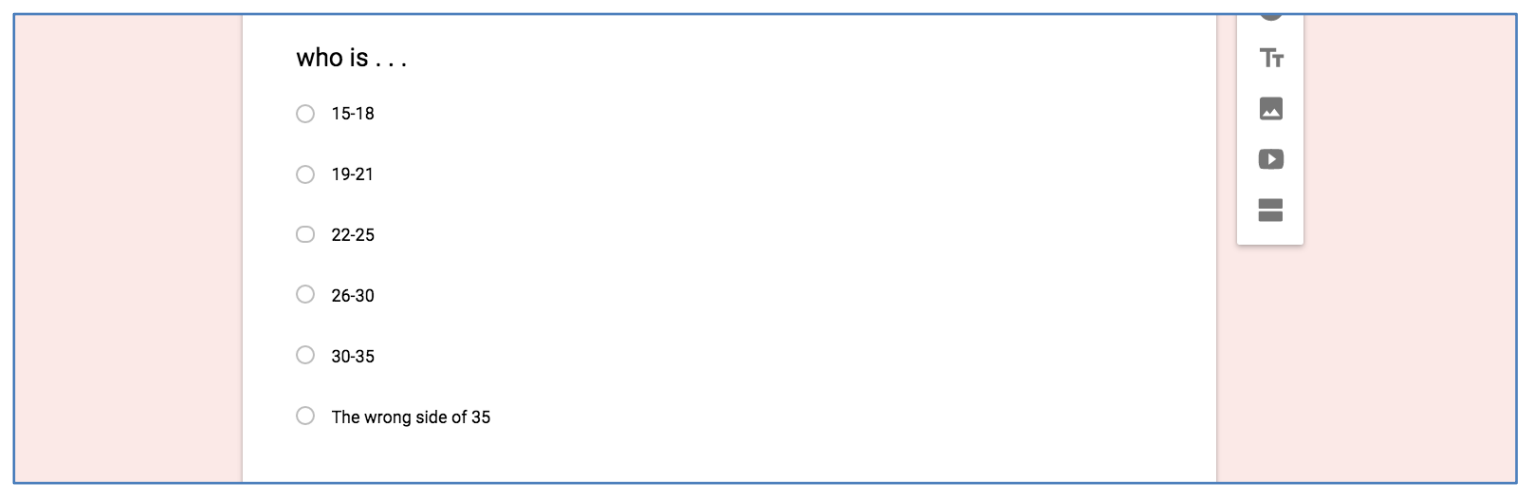

Figure 5: Multiple Choice Type Questions 1

To begin filling in the form, students had to give their names, their character's name, choose a profile name for the character as well as an opening line. One of the most notable of these was for St. John Rivers of Jane Eyre, who had the profile 


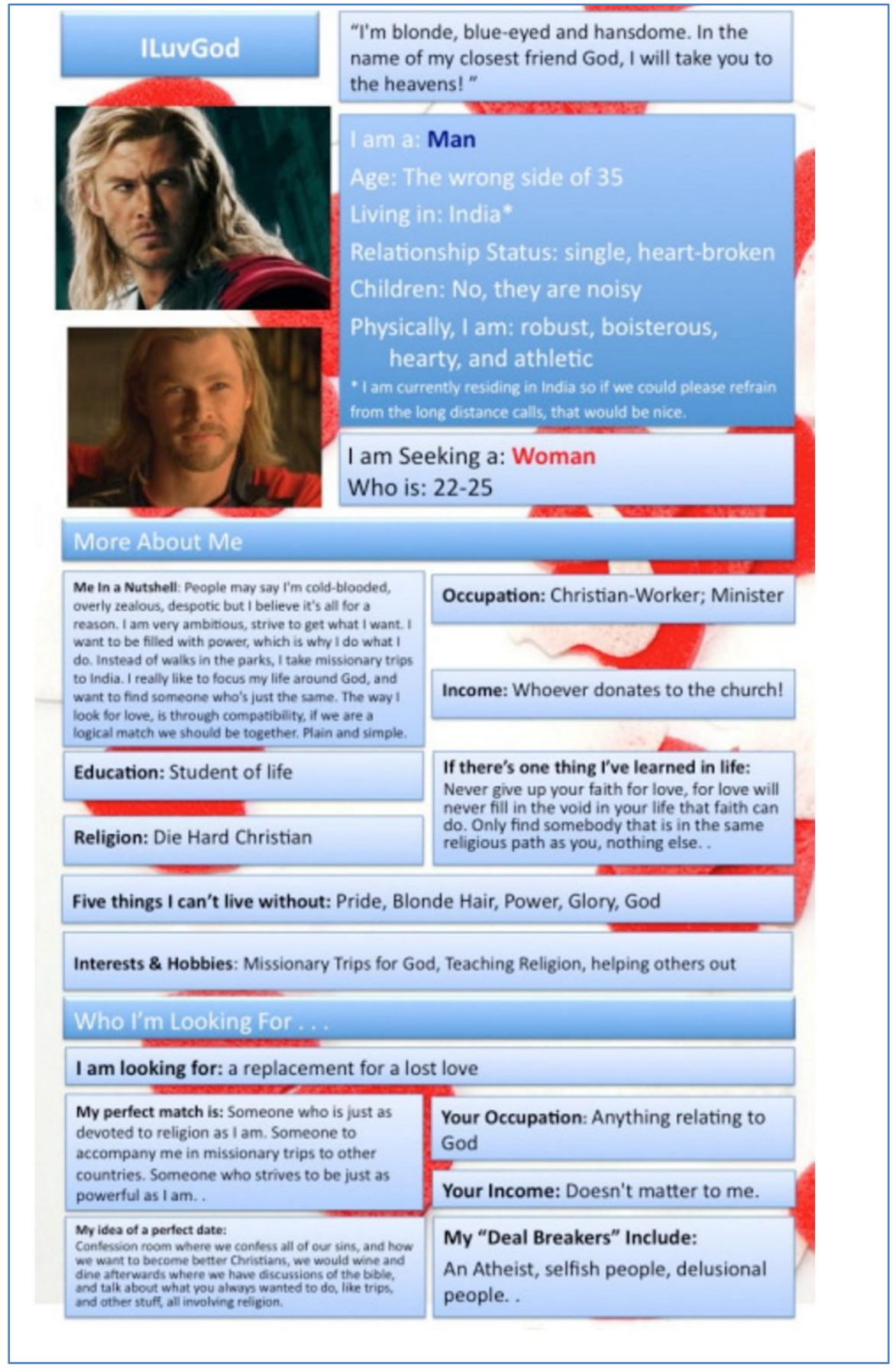

Figure 6: Student Profile for St. John Rivers of Jane Eyre

name "ILuvGod" and opening line, "I'm blonde, blue-eyed, and handsome. In the name of my closet friend God, I will take you to the heavens!" [Figure 6]. 
In addition to the usual biographical fare, students were asked also to supply pictures, describe a perfect date, articulate "One thing I've learned in life" and enumerate their "Deal-breakers." A pair of male students achieved great comiceffect with their response to this last category for "Formator" of Mary Davys's The Reformed Coquette. Deal-breakers: "Poor. Stubborn. There are no other deal breakers because I am confident that I could fix anything I deem wrong with the girl, given enough time of course" [Figure 7].Overall, student responses were

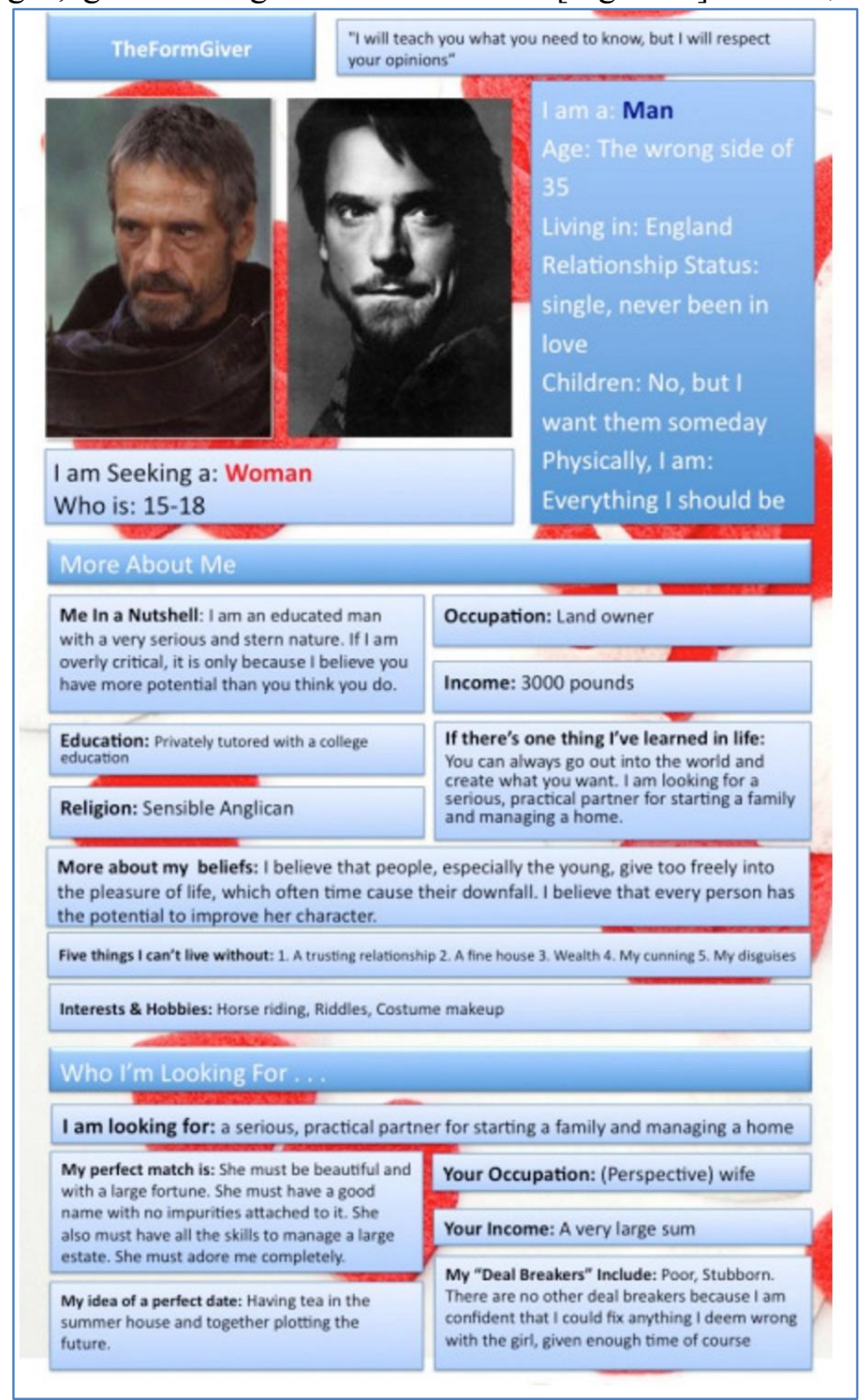

Figure 7: Student Profile Formator from The Reform'd Coquette 
faithful to the texts while showing an inclination to be critical of leading men. My male students in particular seemed to have little patience with eighteenth-century masculinity. For example, one pair had Edward Ferrars respond to the questions of "What is your idea of the perfect date?" and "Income" with "I'm not sure, my mother will have some ideas" and "Until recently I solely depended on my mother," while another pair christened Sir Peter Osborne of The Victim of Prejudice with the profile name "Undesirable\#1" and responded to the question "One thing I have learned in life" with the venomously understated, "You can never be too assertive."

The students developed twenty unique dating profiles for characters ranging from Mrs. Jennings of Sense and Sensibility to Wilmore of The Rover - the latter of which students exuberantly reimagined in the image of Johnny Depp's Captain Jack Sparrow [Figures 8, 9].

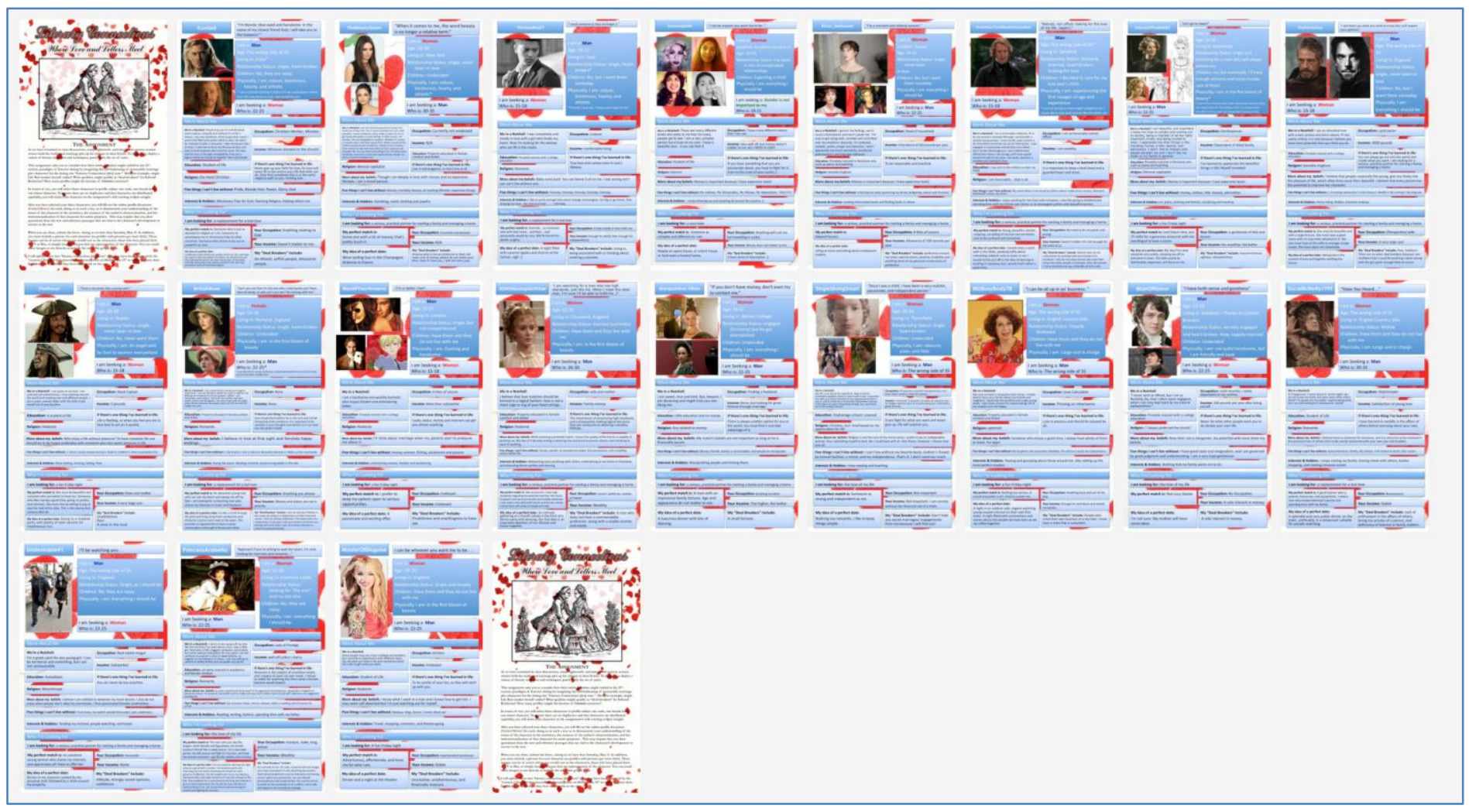

Figure 8 


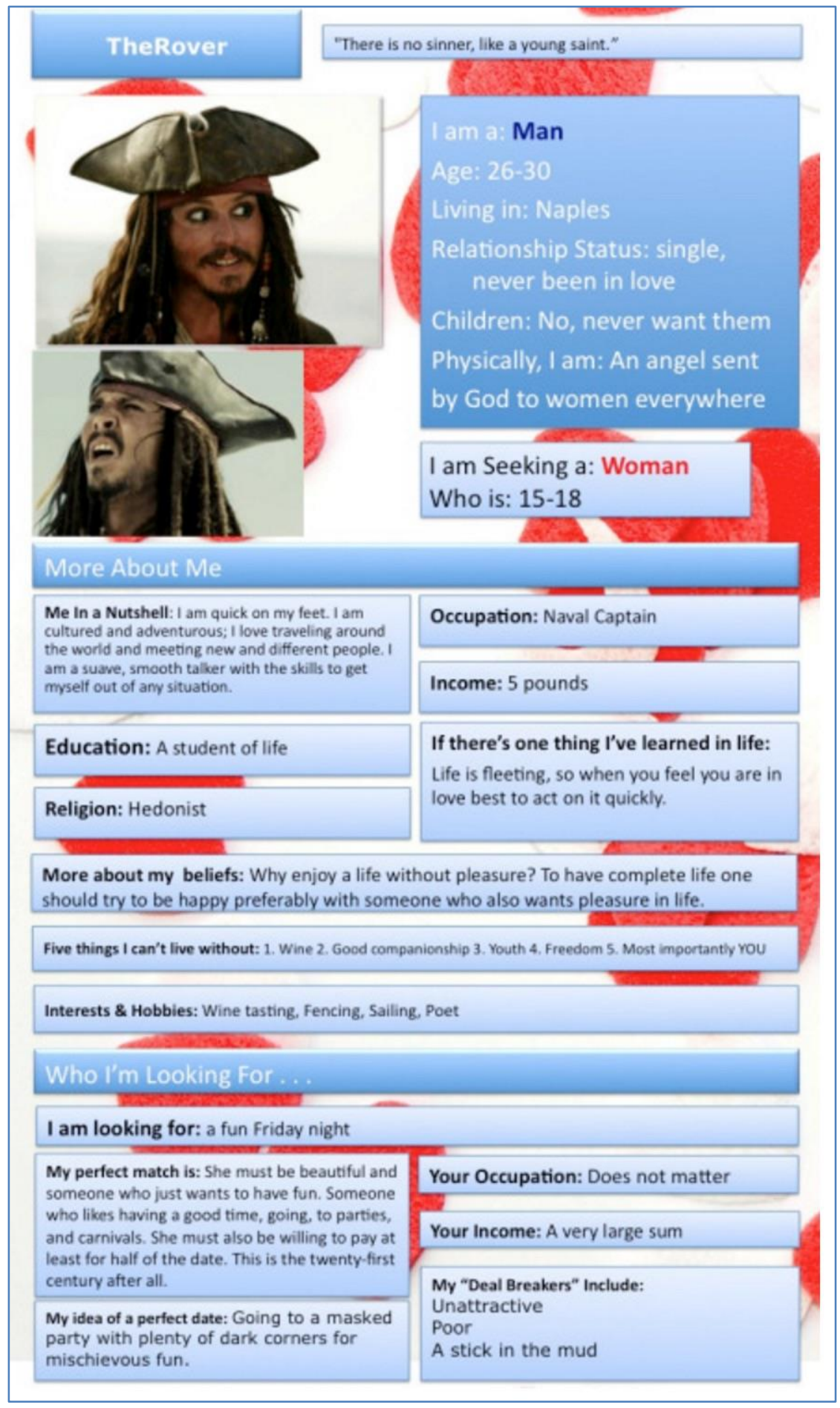

Figure 9: Student Profile Wilmore from The Rover 
As with "Arabella's Valentines," we posted the Tumblr of profiles to the English Department's website, and students shared their work with friends and families through Facebook and Twitter, experiencing the same if not more excitement in seeing the website "tweeted" and "liked" on their Facebook pages.

\subsection{Class discussion}

I launched the Tumblr at the class meeting immediately following the project's due date, and during class we went through each profile on the screen, trying to guess the identity for each pseudonym, and, if possible, which team of students had created the profile. To say we had a good time would be a great understatement. The students were continually laughing, a sign in my eyes of how familiar they had become with these characters and the special affection that they had developed for some-especially Wilmore. After our guessing game, we talked about which characters might have made either prudent or "karmic" as one student put it, matches with each other, not limiting ourselves to those that had profiles, but rather spanning the entire course archive. This too was a joyful exercise.

After our laughter subsided, we then had an extended class discussion about what students had learned about the relationship between the marriage market and gender in the texts they read, with the most popular answers commenting on the age discrepancies between women and men, the explicit and dominant role of money in negotiating matches, and the commercial objectification of women. Students passionately addressed, for example, the gender hypocrisy of giving Edward Ferrars's checkered past a pass while female characters lived in fear of even the rumor of misconduct, or tolerating Wilmore's libertinage while surrounding women with ruinous sexual predation. Connections easily followed to contemporary asymmetries that remarked on how far Western culture has progressed and what work remains.

\subsection{Digital Pedagogy Discussion}

These assignments help students to ask questions of difficult texts-difficult questions about the relationship of gender and culture by playfully inviting them to embody characters. Students wrote on their evaluations that these were their two favorite parts of the class and that they wished they did more work like this in their English classes. Some added that the activities helped them to think about the characters "more deeply" and even come to like the books. My sense is that these assignments were successful because the digital displacement and playfulness of the assignments took the pressure off of students who are less acculturated to the academic practices of essay writing and more at ease on Facebook. While they still produced papers from these work, the assignments created a long incubation 
process in which students were continually close-reading and analyzing the texts and were therefore prepared to generate confidently-informed written work.

From the model of these digital assignments, I have used the platforms of PowerPoint, Google, and Tumblr to create more activities involving critical roleplaying that engage difficult texts like Tristram Shandy and Peri Bathous, which you can see here. [link to http://www.melanieholm/digitalPedagogy]. Since the original issue of these assignments, I have crossed over from using PowerPoint to using Google Slides for images and templates formation so that there are no "pay" applications involved in the process. I am mindful that there is some risk of seeming to endorse products or corporations even though the technologies are free. I try to mitigate this by explaining to students that alternative technologies would work just as well-WordPress, Facebook, Flicker, Instagram, Pages, and so forthemphasizing that my choice of digital resources was facilitated not by any substantial criteria; rather, these were just the tools best known to one Luddite, "Digital Immigrant," professor.

\section{Work Cited}

Prensky, Mark. From Digital Natives to Digital Wisdom: Hopeful Essays for 21st Century Learning, Corwin, 2012. 


\section{Appendix A: "Be My Quixotic Valentine!” Assignment}

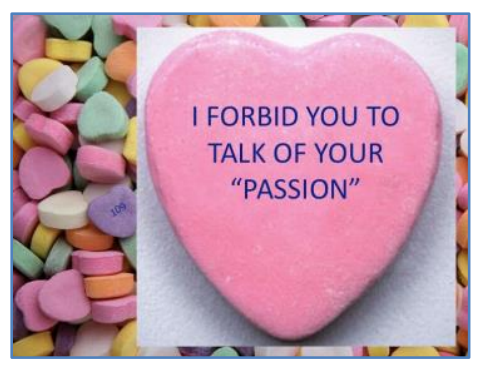

As we have seen by comparing episodes of Don Quixote with The Female Quixote, Lennox's heroine Lady Arabella can be understood as a satiric reinterpretation of Cervantes's already satiric figure Don Quixote. Although Arabella has roots in Cervantes's comic fiction, her belief in Romance extends and complicates the object of satire; for although Cervantes ridicules Romance, in The Female Quixote the absence of "Romance" from the contemporary marriage market and the object status to which the market relegates women are more sharply criticized than the absurd Romance dramas that fuel Arabella's laughable "damsel errantry."

One of the ways that Lennox clues us into this vital secondary criticism is by defamiliarizing contemporary customs, a feat she achieves by reframing them in Arabella's perspective of Romance and Courtly love. The vehicle through which this perspective is shown is not narrative explication, but dialogue: It is through Arabella's speech that we get both her comical, Romantic interpretations of contemporary customs and, more often than not, her critical rejection of them.

For this assignment, I want you to:

1. Find three (3) episodes in the text in which Charlotte Lennox uses Arabella's voice to comically critique contemporary beliefs about gender and marriage through Romantic interpolation.

2. Post the passages and page numbers (from the course edition!) to Blackboard, email them to me, or tweet them to \#QuixoticValentines.

3. Insert the passages and page numbers into the anti-valentine PowerPoint template available on Google Drive for download, saving your work under "Save as Image." 
4. Upload "jpg" image to the Tumblr: www.QuixoticValentines.Tumblr.com

5. Write a textual analysis (900 words) that explains your logic in choosing these three passages by employing close reading as you break down the language choices of the text. 


\section{Appendix B: The Technology of "Arabella's Valentines": How to use PowerPoint and Tumblr}

\section{Template Creation and Image Production}

1.1 I made the blank template [Figure 10] through PowerPoint by combining two images, a field of candy hearts with one large heart superimposed, and created simple text boxes on the purple heart and main pink heart for page numbers and passages.

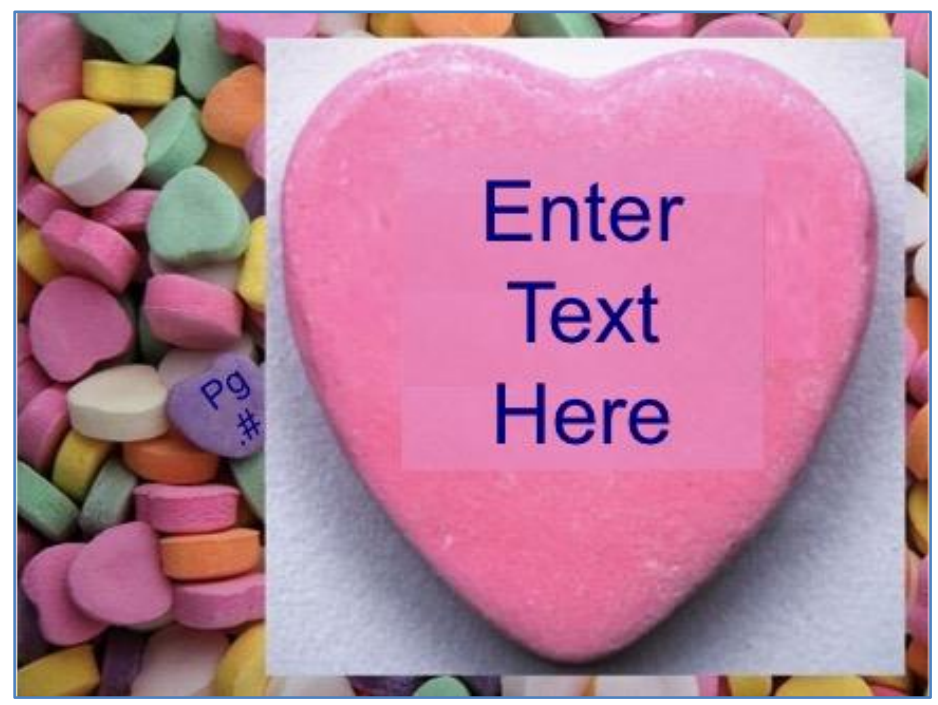

Figure 10: Blank Template 
1.2 To create their own dialogue images for the assignment, the students needed only to select "Save as Picture" once they had inserted their text and page numbers, selecting the option of "jpg" for the image (Figures 11, 12).

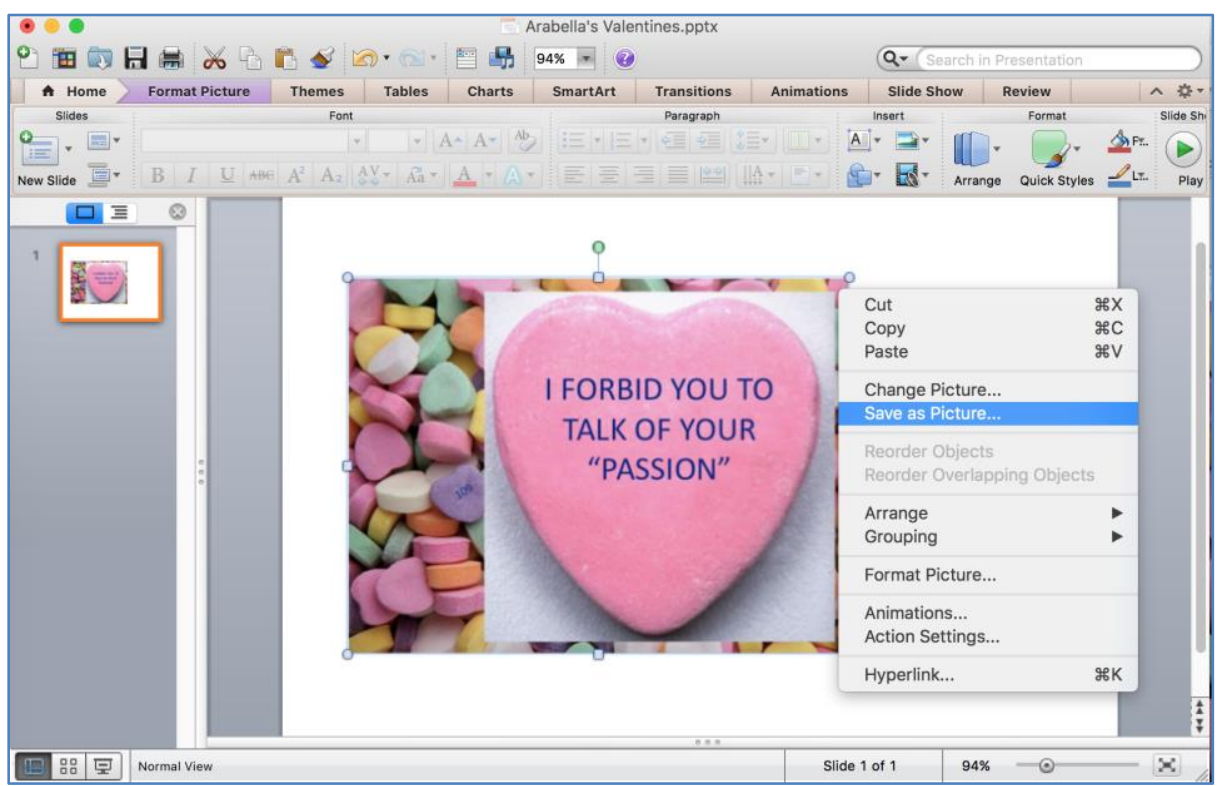

Figure 11: Save as Picture 


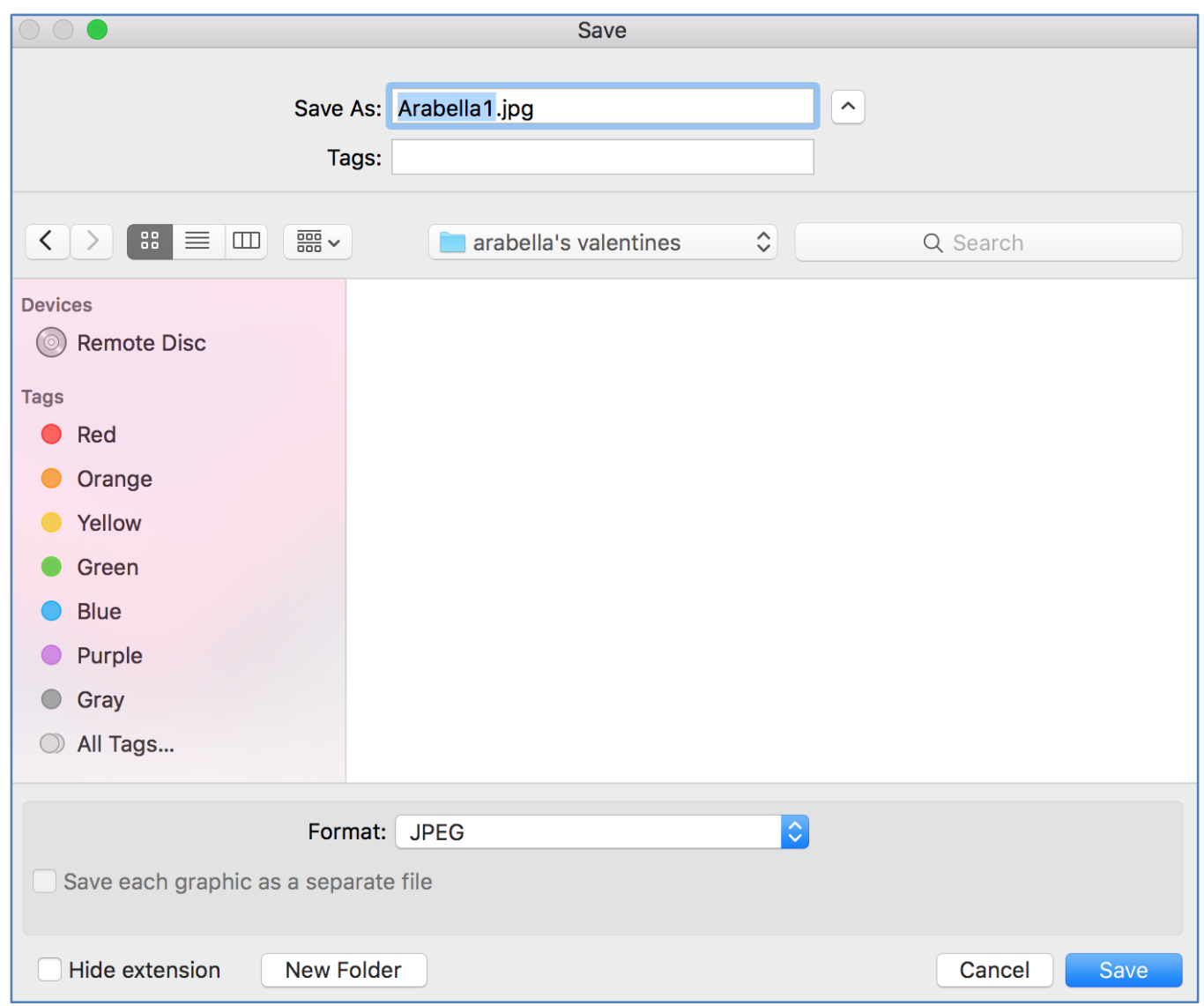

Figure 12: Saving File as JPEG

\section{Tumblr Creation and Uploading to the Site}

The next step for students was to upload their image to a Tumblr I had created. Tumblr is a free content hosting/social media site that allows you to create blogs. For this assignment, each image a student creates is uploaded and presented as a blog post. Tumblr creation is thankfully quick and easy and requires no coding knowledge, though some knowledge can help you to customize your space. More importantly, Tumblr is free and it is a platform with which platform most students are more or less familiar.

2.1 To create the Tumblr I went to www.tumblr.com where I already had an account, though setting one up is only as difficult as supplying a user name and password. 
2.2 When logging in or after creating an account, you are brought to the dashboard page. To create the site (or "blog" as Tumblr will refer to it), I pressed the account icon on the upper right hand side of the page [Figure 13]. I then moved forward to click on the "+ New" to create my own space.

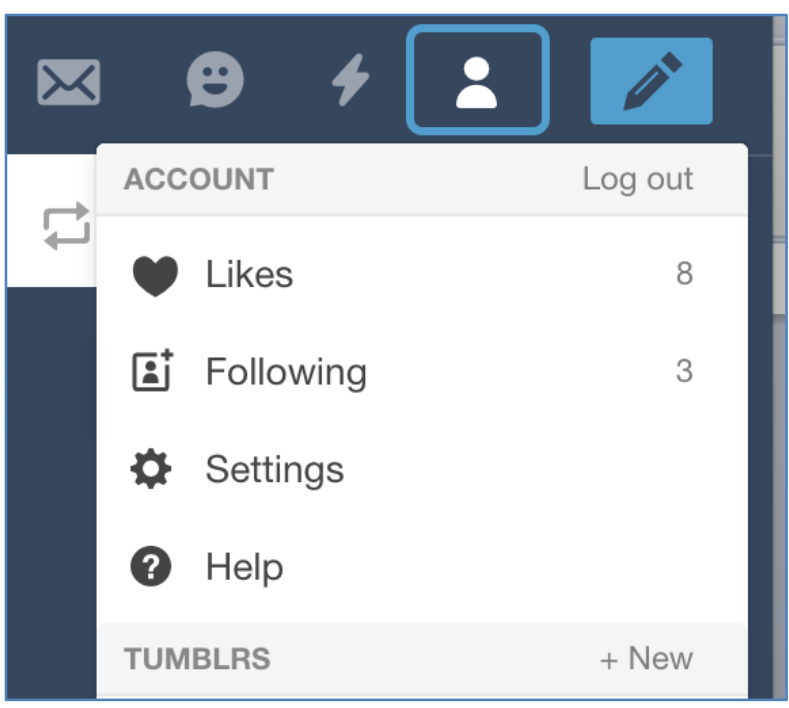

Figure 13: Blog Creation

2.3 The next screen asked me to provide a name and web address for the project, which for this project were "Quixotic Valentines" and "quixoticvalentines.com" [Figure 14]. 


\section{Create a new blog}

This additional blog can be managed by multiple authors or set to private.

Note: If you want to Like posts or Follow other users with this blog identity, you must log out and create a separate account. Learn more about Primary vs. Secondary blog features here.

Title

Quixotic Valentines

URL

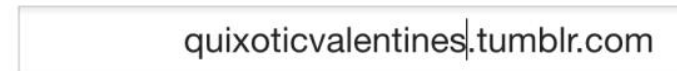

Privacy

Password protect this blog

This blog can only be viewed by people who enter this password: (ie. Acme Corp, Sara \& Jacob, My Awesome Blog)

(you can change this at any time)

Are you a robot?

I'm not a robot

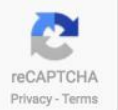

Figure 14: Naming the Blog

Pressing the "create blog" button in the lower-left hand corner then took me back to the dashboard screen.

2.4 From the dashboard screen, the next step was customizing the blog. To do this, select "Edit Appearance" [Figure 15]. 


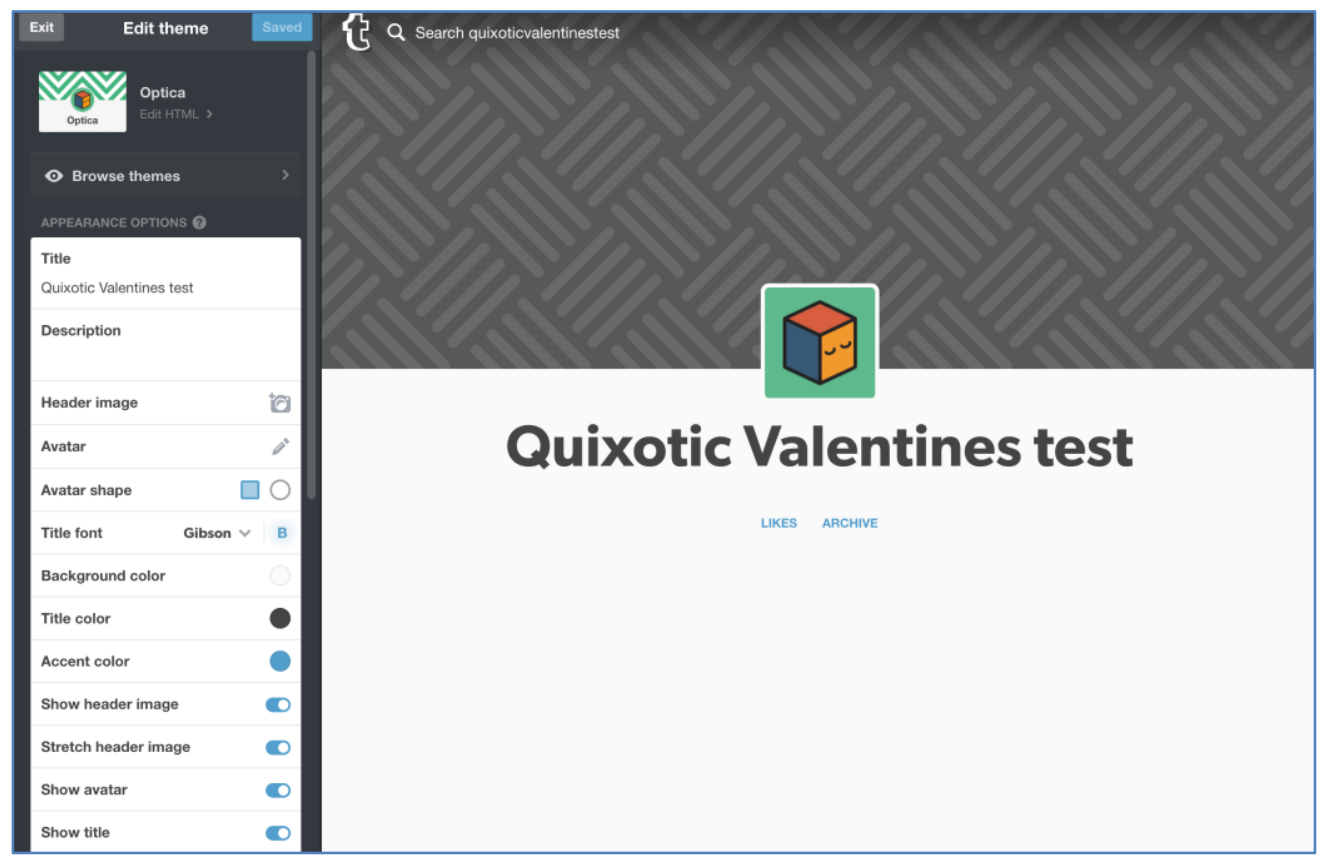

Figure 15: Dashboard Menu Right-Hand Side

Selecting "Edit Appearance" brought me to a screen that allows for customizing how the site will look [Figure 16].

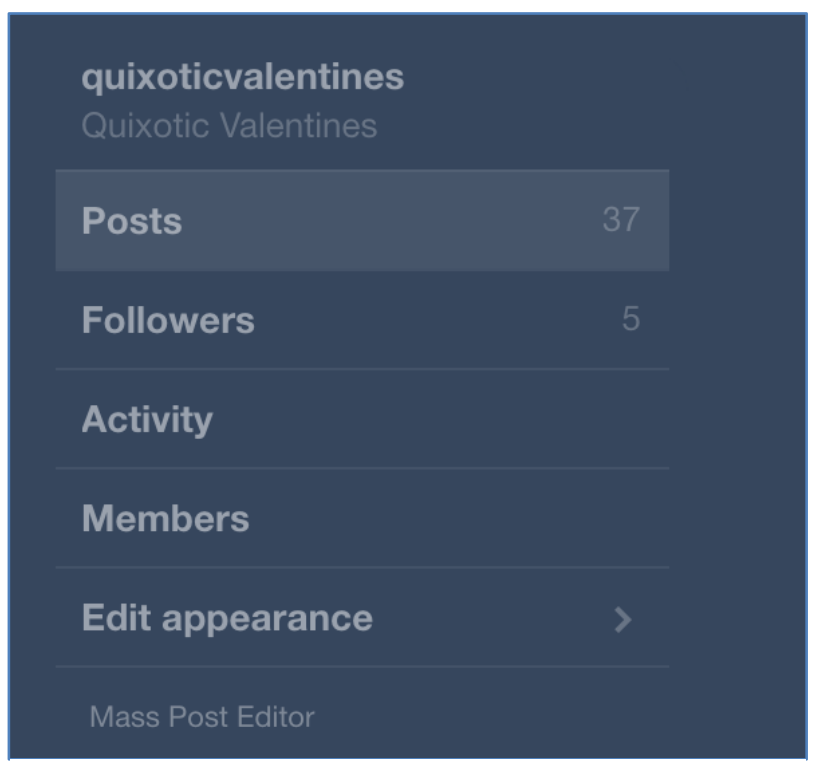

Figure 16: Edit Appearance 
2.5 To affect the overall "look and feel" of the blog, I selected "Edit Theme," which allowed me to pick a theme or template for the tumblr [Figure 17]. For this tumblr, I wanted to have a simple display of unfolding of images. While the default theme is "Optica," I chose a free theme called "The Modernist" for my site by clicking on the button "Browse Themes." This button opens up an array of free and pay themes. The free themes are at the end of the scrolling list, and there are many more to choose from if you select "Search waaay more themes" at the bottom of the menu.

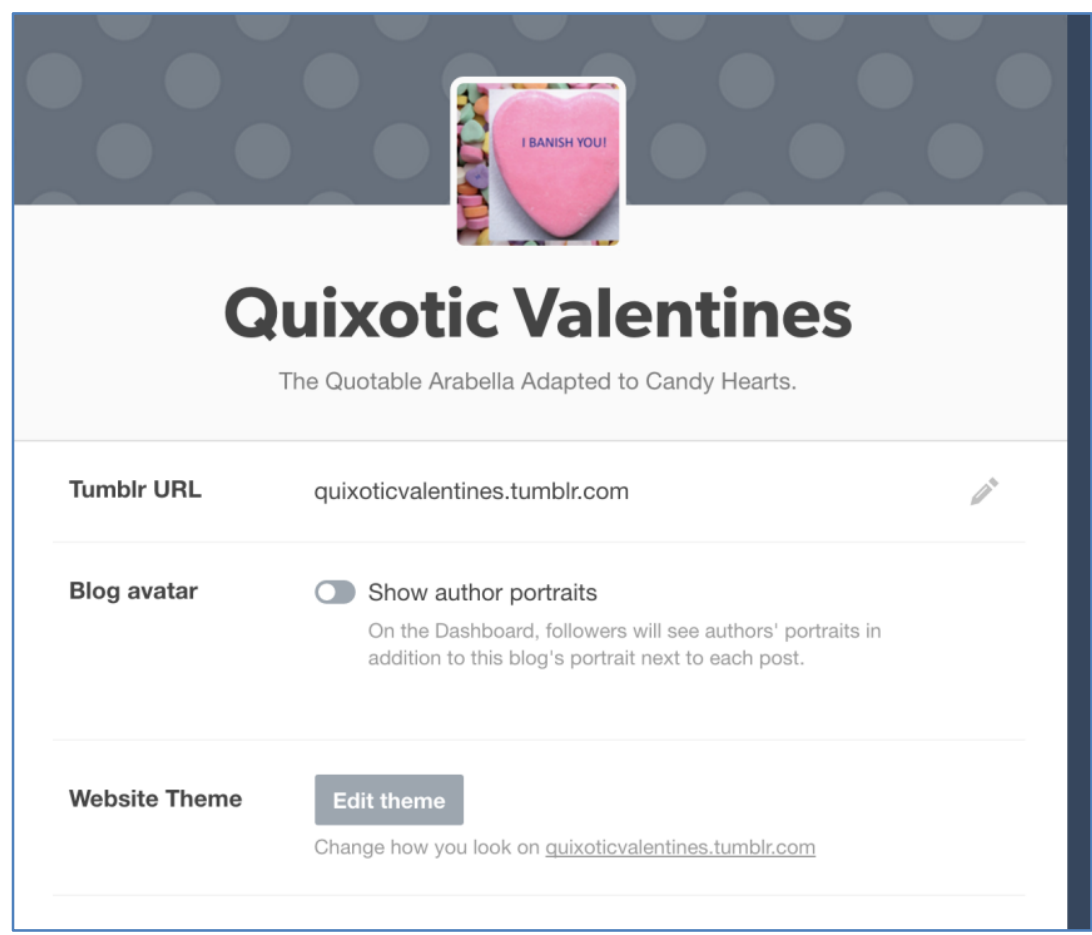

Figure 17: Editing and Browsing Themes

2.6 After selecting my theme, I added a description and title, saved my work, and then exited by pressing the "Save" and "Exit" buttons [Figure 18]. 


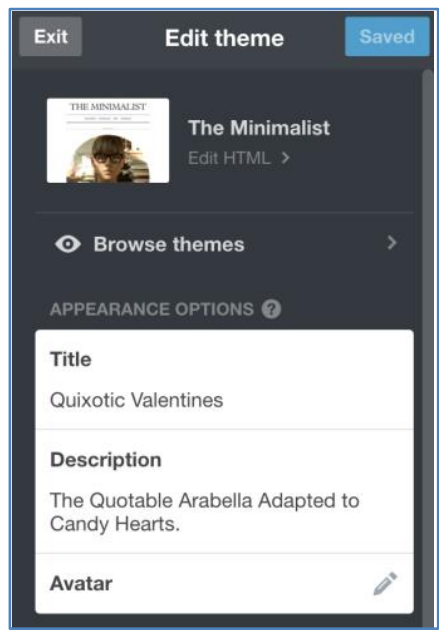

Figure 18: "Save" and "Exit"

2.7 Exiting from Edit Themes returned me to the Edit Appearance menu. Now that I had created a theme that I was comfortable with, it was time to begin uploading ("posting") and allowing students to post. To return to the home screen and begin posting, I clicked the home icon on the top of the page [Figure 19].

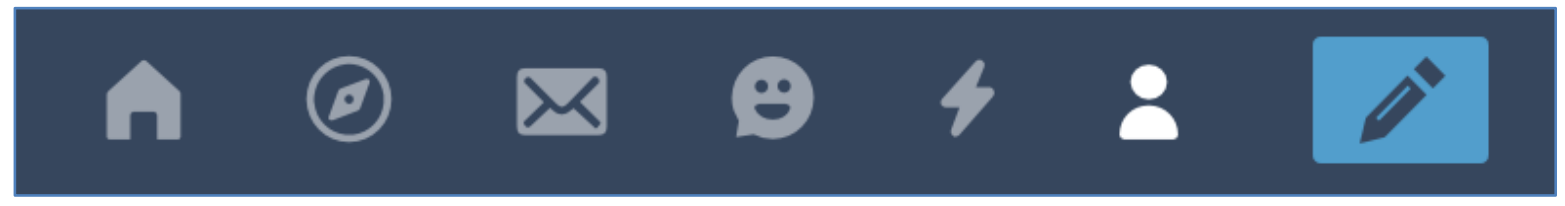

Figure 19: Dashboard Icon Menu: "Home Icon" on Far Left; "Edit Icon" on Far Right

2.8 From the home screen, to upload pictures as blog entries, all I or my students needed to do was click the photo icon from the screen and then click "Upload Photos" [Figures 20, 21]:

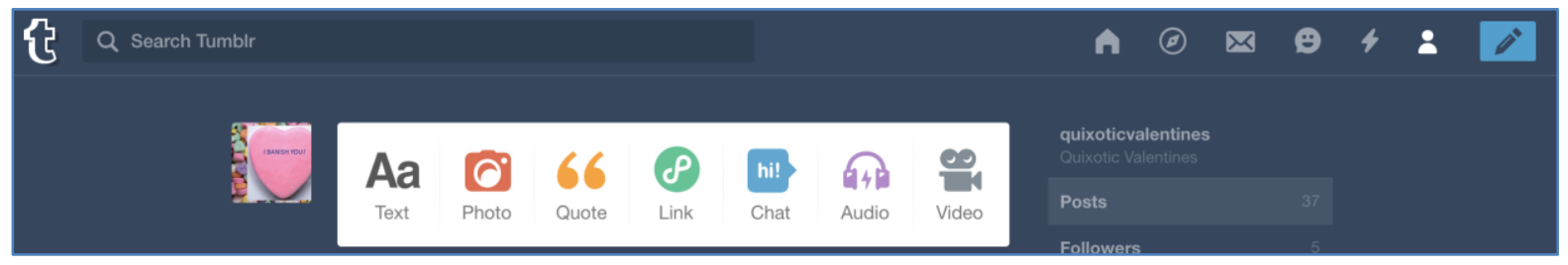

Figure 20: Dashboard Icon Menu (Upper Right); Blog Entry Type Menu (Center) 


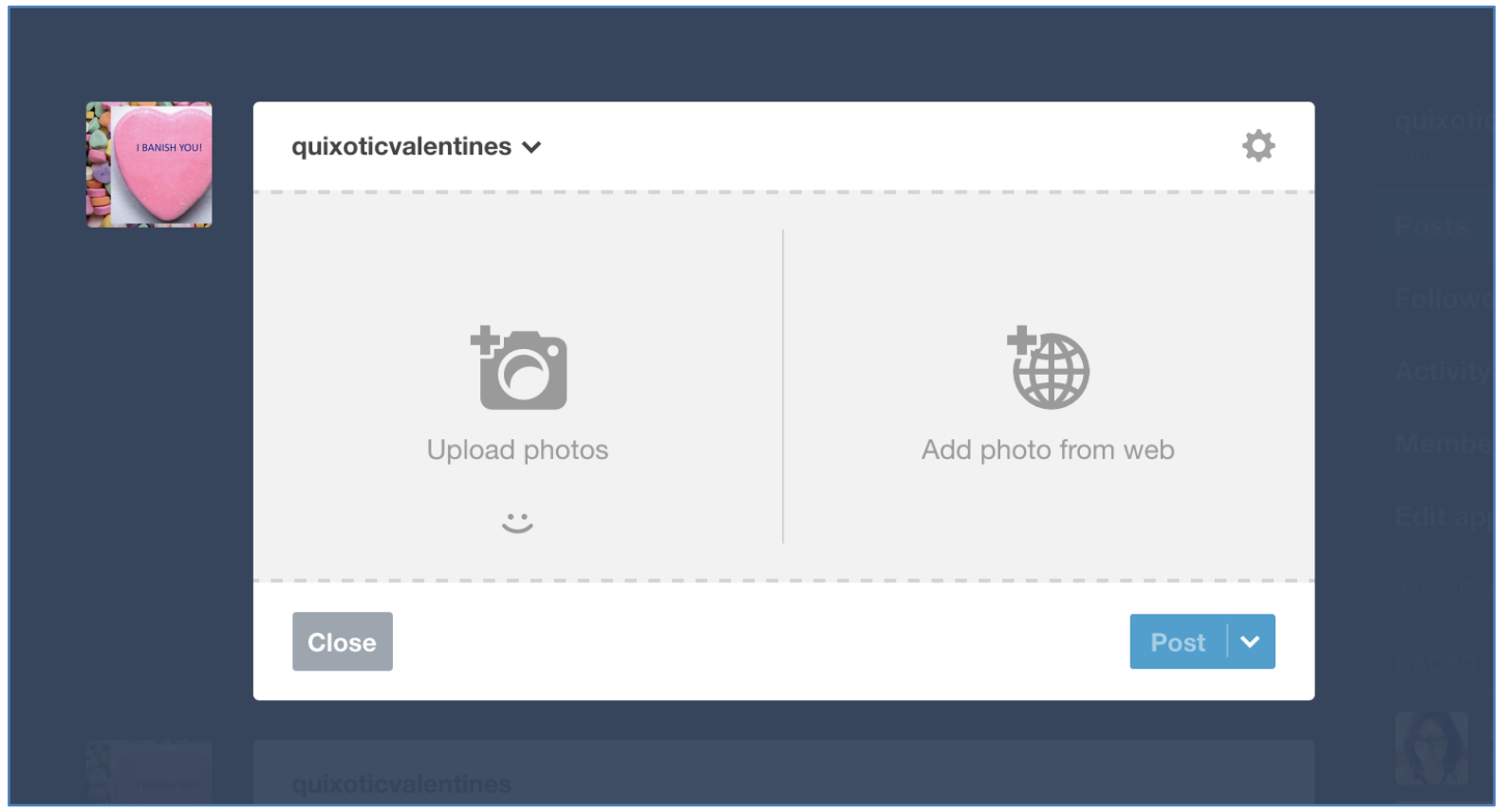

Figure 21: Uploading Pictures 1

And then upload the file from wherever it is saved [Figure 22]:

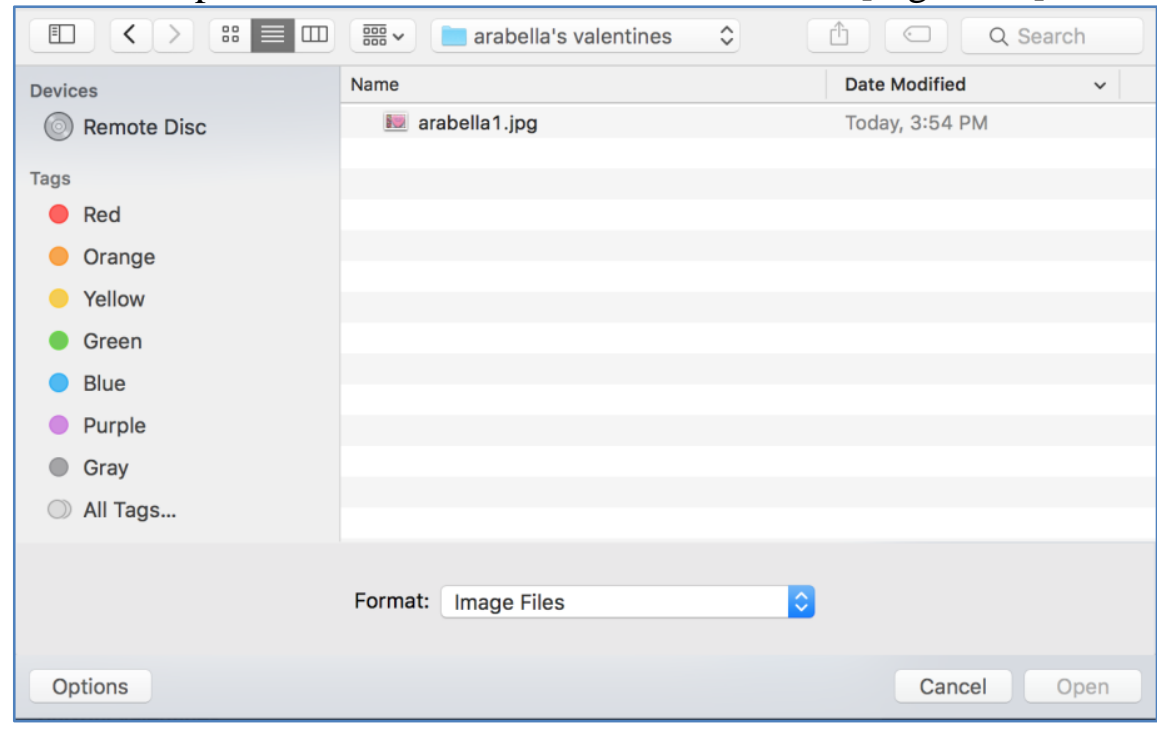

Figure 22: Upload Photo/Image File from Computer Drive

2.9 When the photo is uploaded as the blog entry, you have the option of adding more pictures and text or manipulating the image [Figure 23]. For our project, 
neither was necessary because each image was intended to be a single blog post. When the post is ready, you can publish it by selecting "Post."

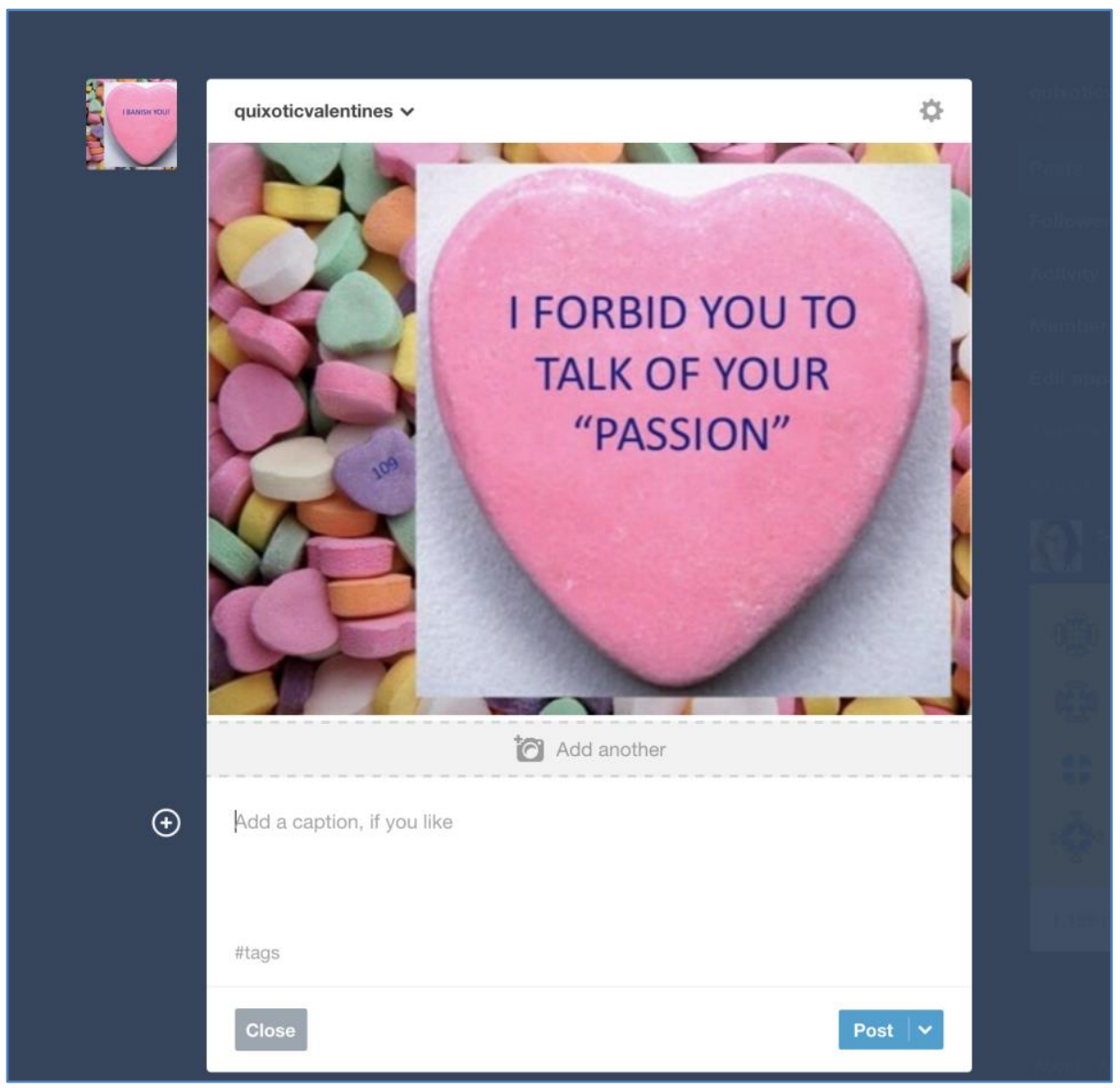

Figure 23: Creating the Blog Post

After my students had uploaded all of their images from the assignment, I uploaded a title page image which I had also made through PowerPoint using the same "Save as Picture" technique, similarly superimposing another image over the previous background and creating text boxes to write out the information about the assignment: the assignment name, the course name, my name as instructor, the university name, the date, and the citation information for the edition of the book we used [Figure 24]. I added this post last because of the blog format posts entries from most recent to the oldest; therefore, to have the title page show up first to visitors of the Tumblr, it needed to be the last post published.

At this point your Tumblr was done, though your Tumblr can be considered active as soon as you create your first post, and it can always be added to or edited as time goes by. 
ABO: Interactive Journal for Women in the Arts, 1640-1830, Vol. 7 [2017], Iss. 1, Art. 5

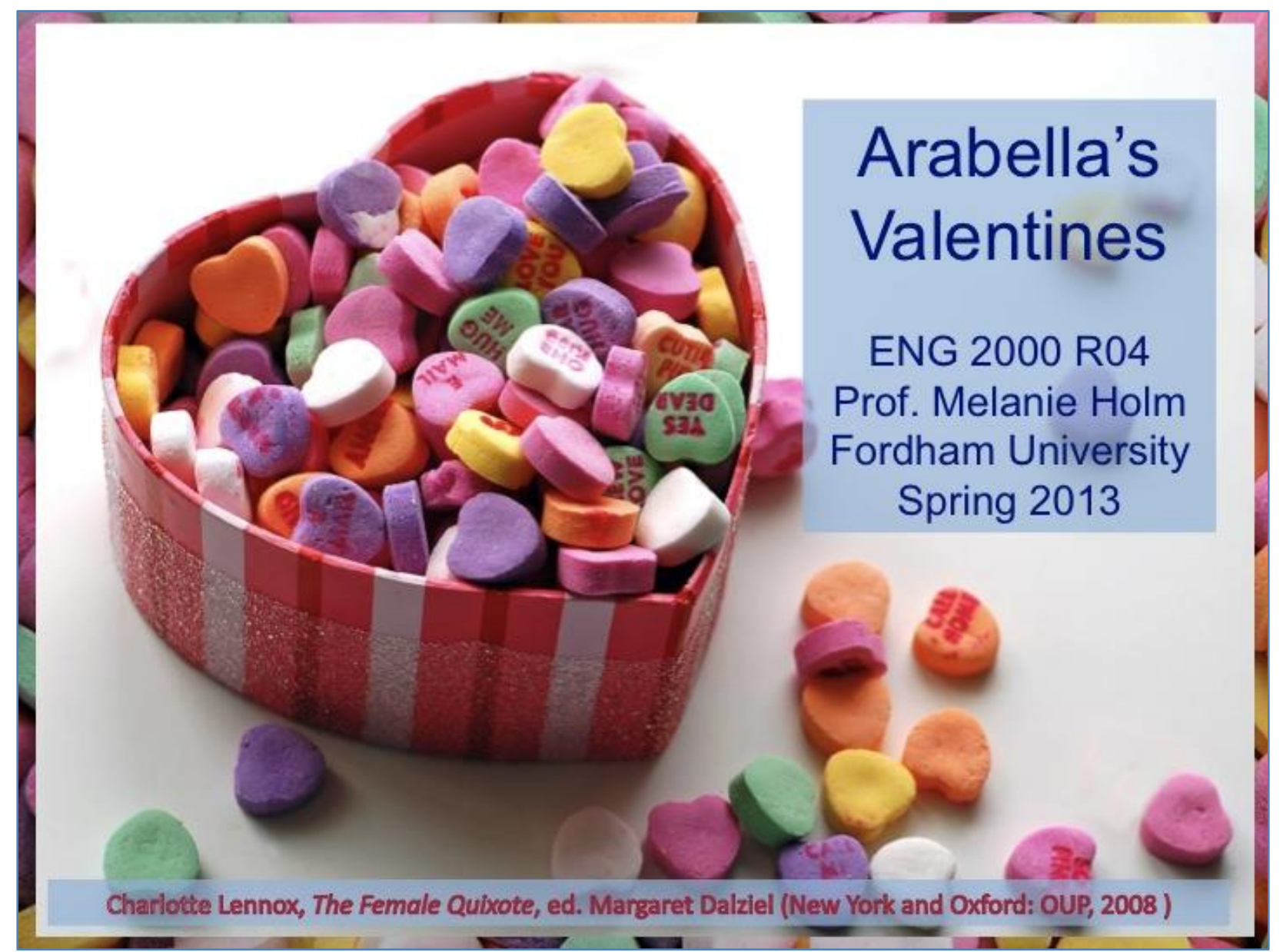

Figure 24: Title Post for Assignment 


\section{Appendix C: "Literary Connections [dot] com" Assignment}

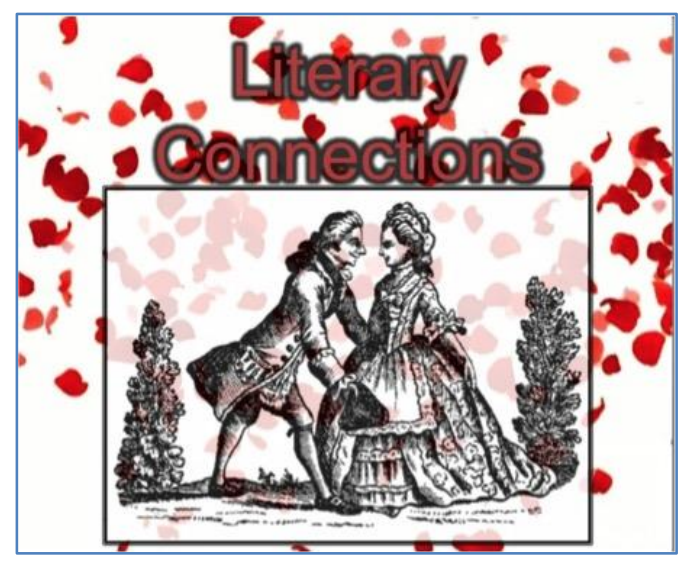

As we have remarked in class discussions, many eighteenth- and nineteenthcentury women writers hold the traditional marriage plot up for critique in their fiction. To do so, they deploy a variety of literary strategies and techniques, particularly the art of satire.

This assignment asks you to consider how their satiric impulses might unfold in the $21^{\text {st }}$-century paradigm of Internet dating by imagining the self-fashioning of memorable marriage plot characters for the dating site "Literary Connections.com." How, for example, might Lily Bart market herself online? What qualities might qualify as "deal-breakers" for Edward Rochester? How many profiles might the heroine of Fantomina construct?

- Part 1: In teams of two, you will select three characters to profile online: one male, one female lead, and one minor character. To ensure there are no duplicates and that characters are distributed equitably, you will claim your character on the assignment's wiki.

○ After you have selected your three characters, you will fill out the online profile document for each, doing so in such a way as to demonstrate your understanding of the status of the character in the narratives, the nuances of the author's characterization, and her instrumentalization of that character for gender satire.

- Part 2: Explain the choices you've made by supplying evidence from the text. I would like you to explicate your representations of the characters by close reading quotations from the text for at least 5 of the profile boxes in each of their profiles (1200-word minimum). 


\section{Appendix D: The Technology of "LiteraryConnections.com": Incorporating Google Forms into Tumblr Projects}

\section{Setting Up an Online Dating Site Using Google Forms}

I created a simple online dating form for my student to fill out with Google Forms in the following way. I logged into my Google Drive account (which you can create if you have a Gmail account or even a regular email, though you must register at www.googledrive.com ). From the main Google Drive menu, I pressed the red "new" button and selected "Google Forms" from the bottom "More" menu [Figure 25].

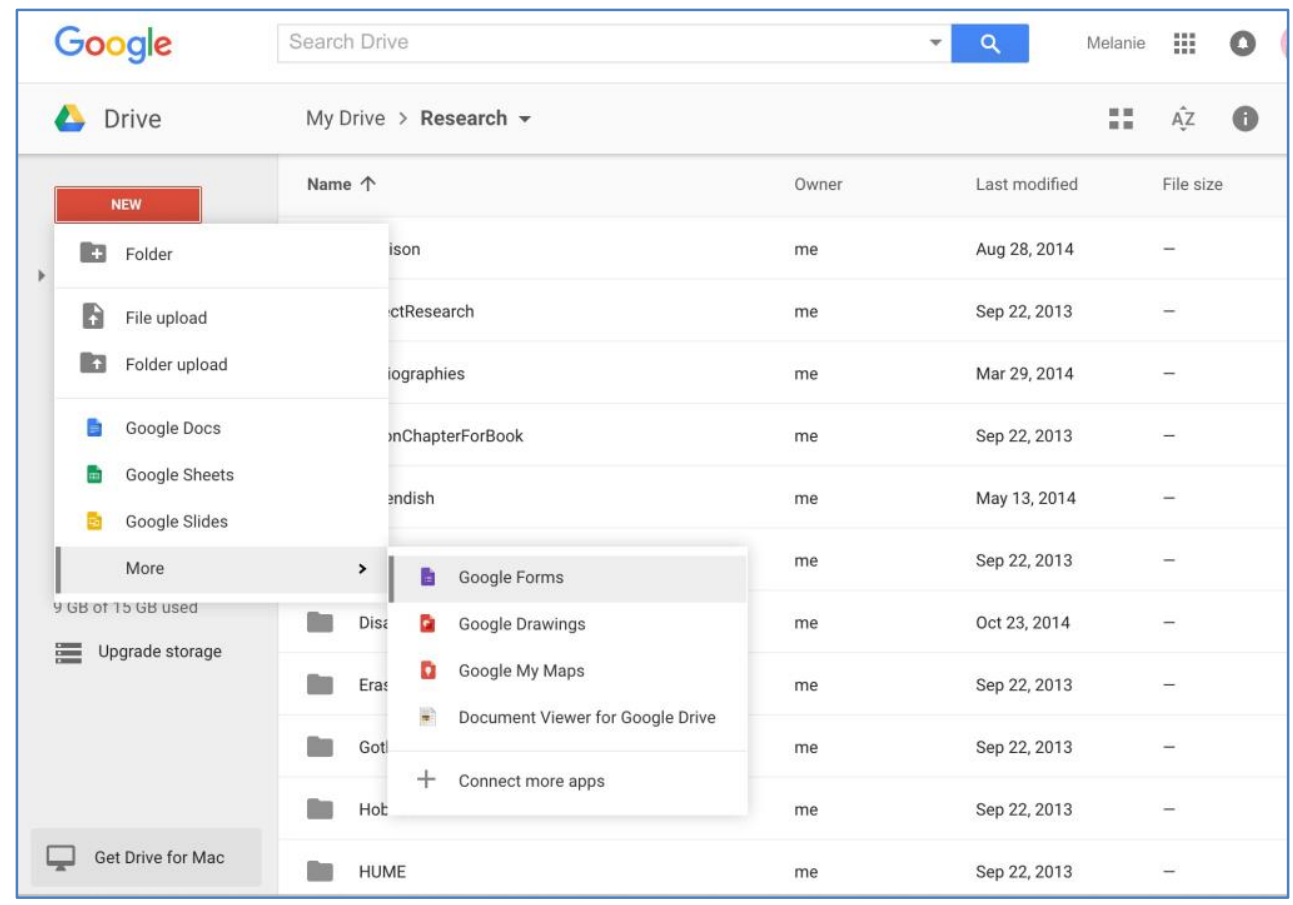

Figure 25: Creating a New Google Form from Drive Menu

The new, blank form opens up in your browser under a separate tab [Figure 26]. There is no need to "save" your work, because all work is automatically saved in Google Drive. 


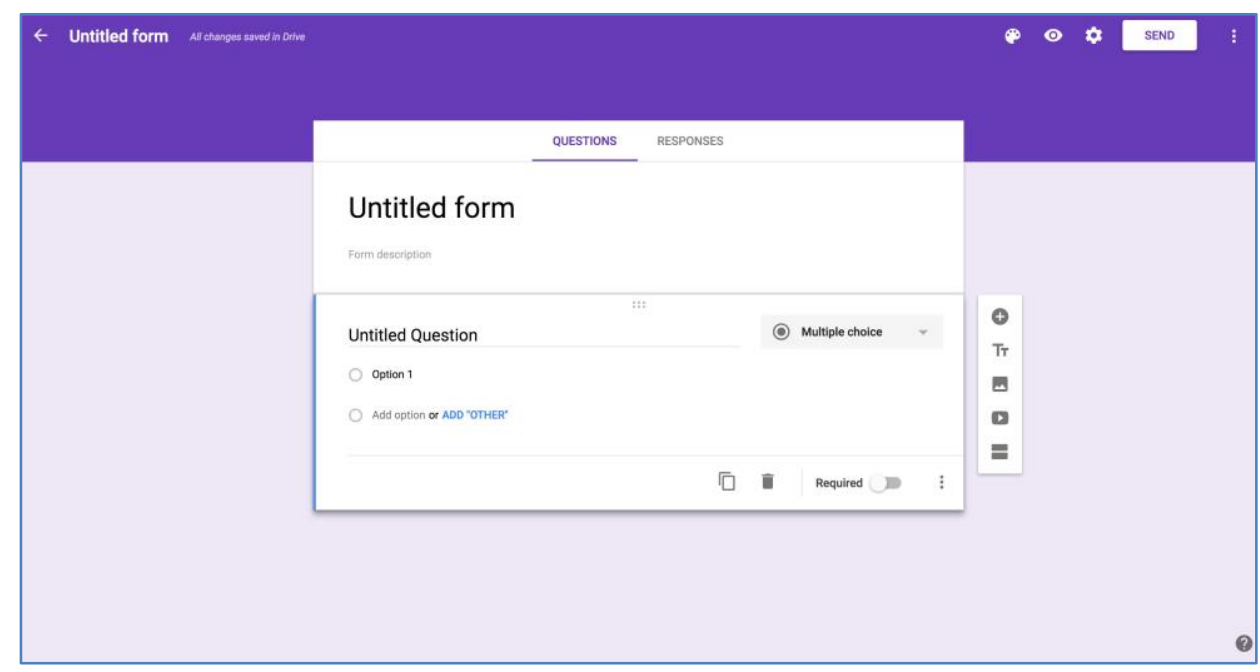

Figure 26: Blank Google Drive Form

Customizing the form is really rather straightforward. Write the title of your form in the space that says "Untitled Form" either in the center or upper-left (they will synchronize), and a brief description or assignment instructions below [Figures 27, 28]. You can add a theme or color scheme to the document by clicking the palate in the upper right hand corner (to select a theme, click on the lower left hand "mountain icon"). I selected a red theme [Figure 27] and added a description below the form title.

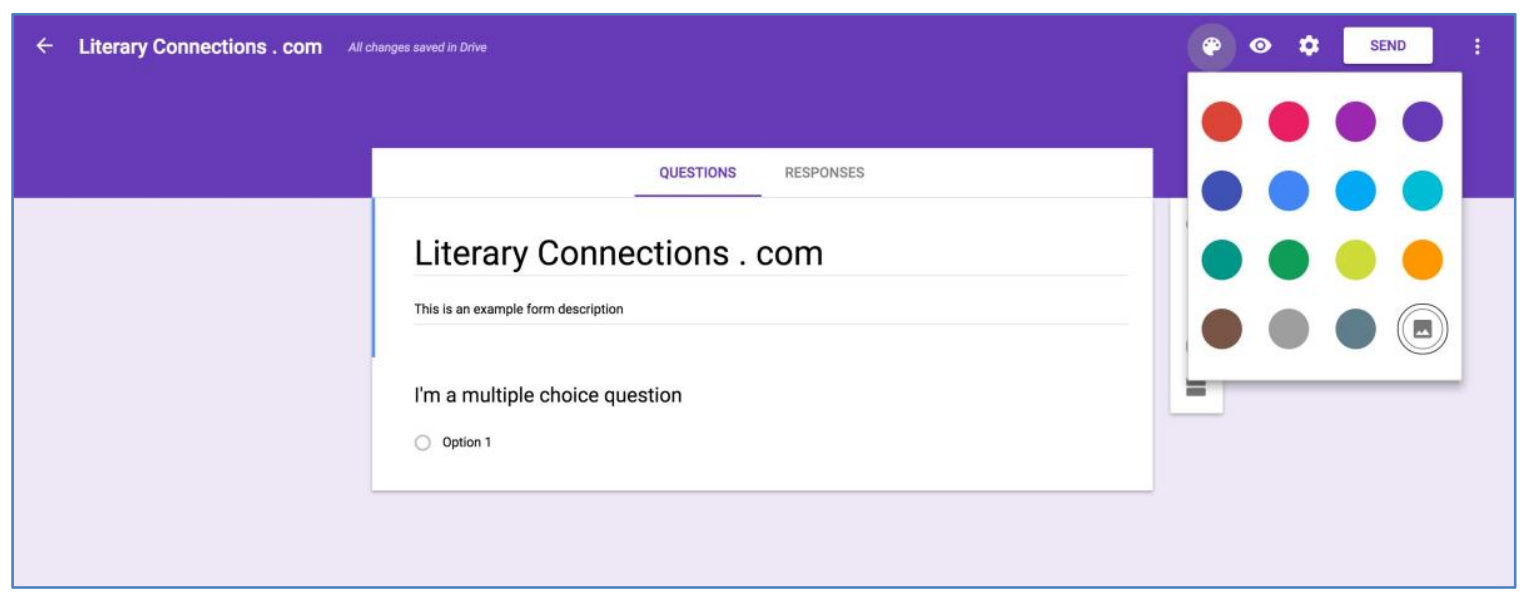

Figure 27: Entering Form Name and Choosing Background "Look and Feel" 


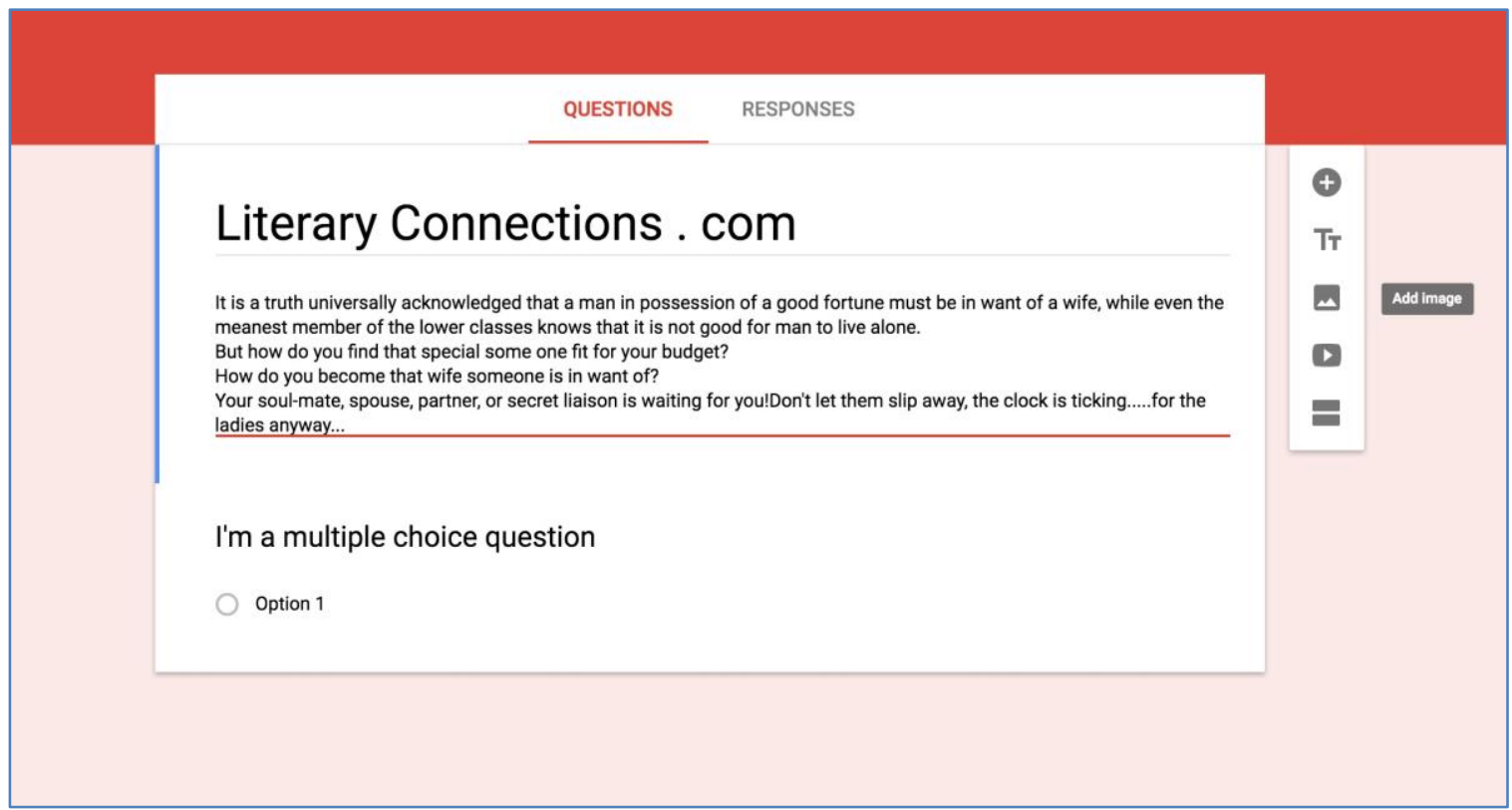

Figure 28: Adding an Image 1, Writing a Description, Changed Background

I then added an image from a file that I created using the strategies explained "The Technology of "Arabella's Valentines": How to Use PowerPoint and Tumblr" by selecting the image icon to the right of the title section [Figures 28, 29, 30]. 
Holm: Playing with Eighteenth-Century Gender Online

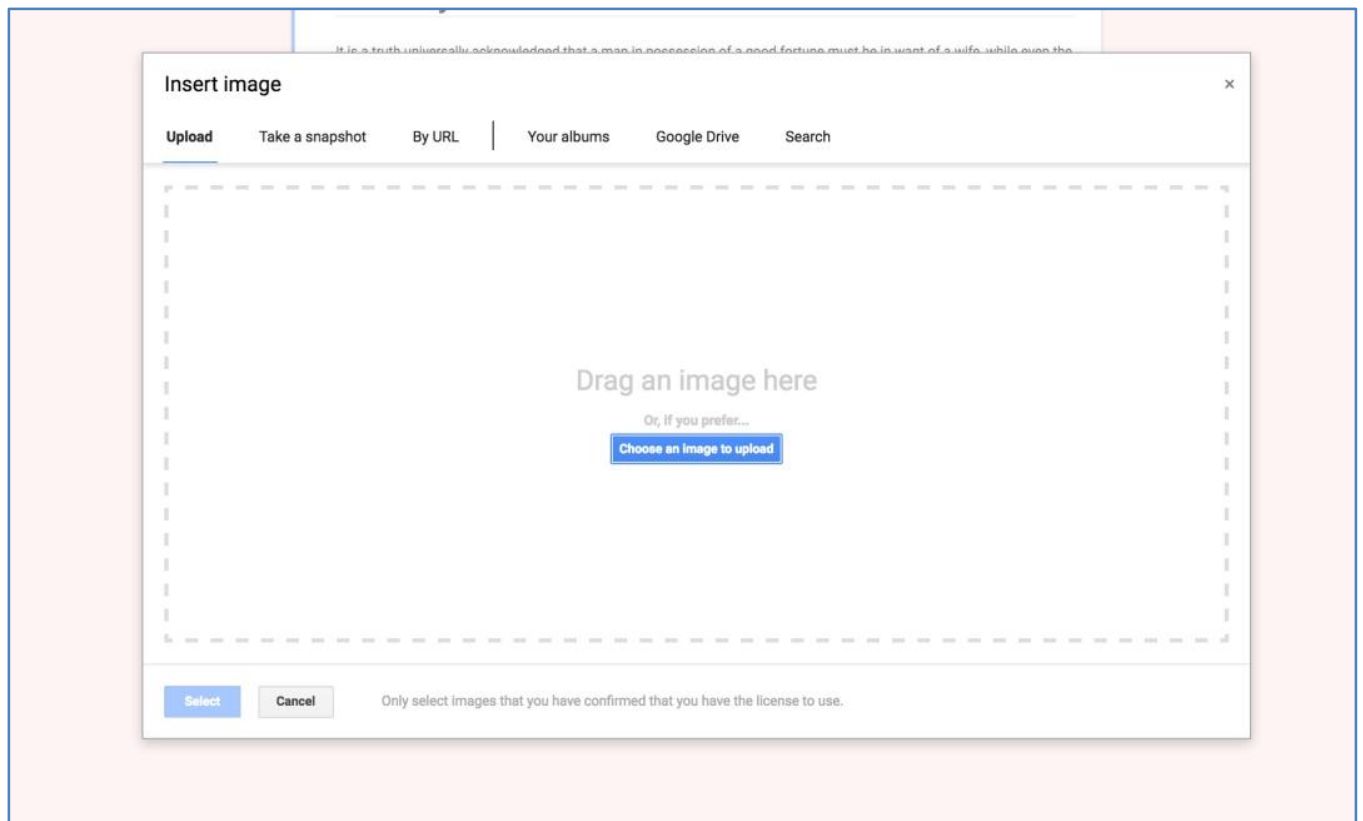

Figure 29: Adding an Image 2 
ABO: Interactive Journal for Women in the Arts, 1640-1830, Vol. 7 [2017], Iss. 1, Art. 5

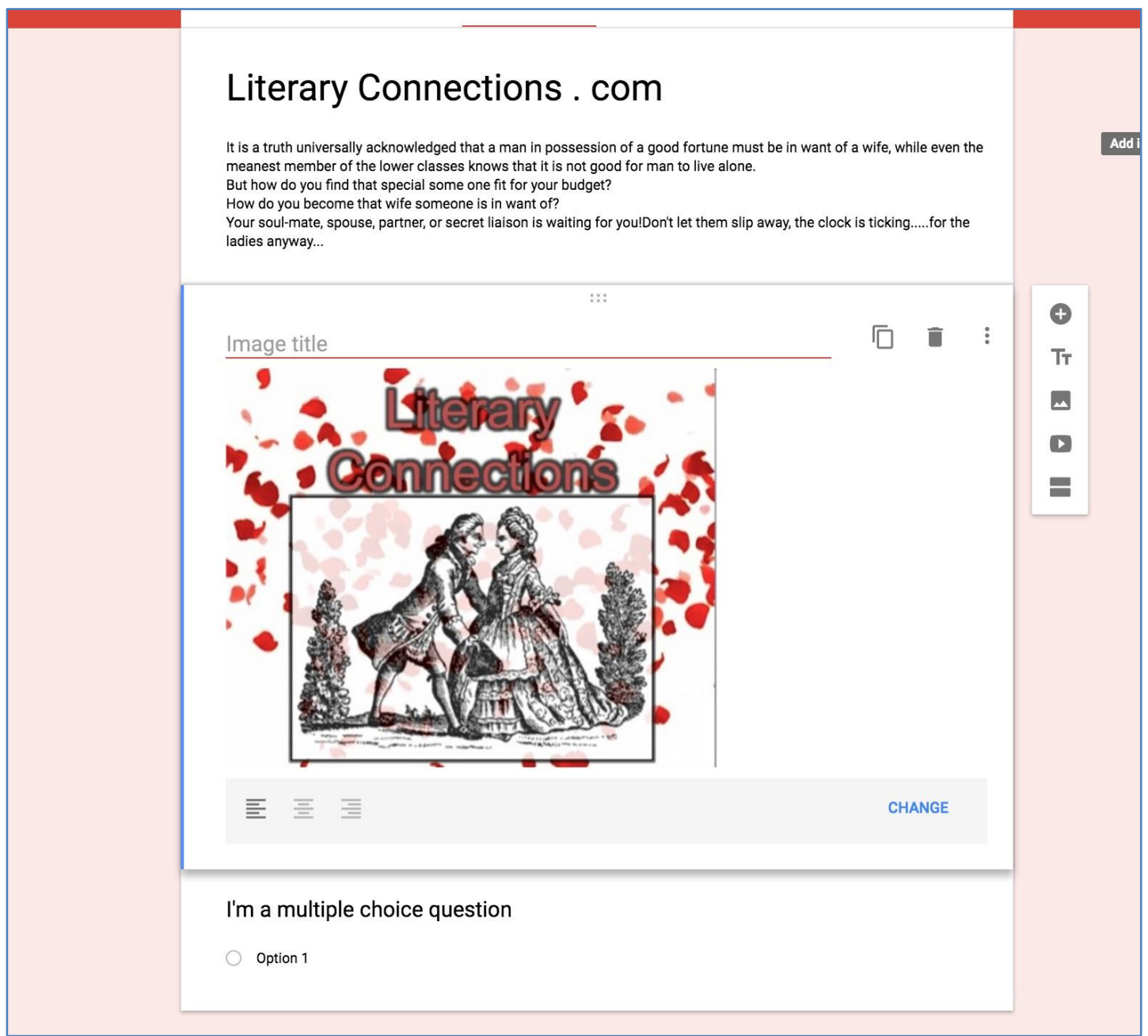

Figure 30: Image Uploaded 
I then began to add "questions" for students to answer that would go into a googlegenerated database. Questions can be of a variety of kinds: short answer, paragraph, multiple choice, check box, drop-down, and so forth. You can add questions by typing the question in the "I'm a Multiple Choice Question" space and selecting what kind of question you want it to be. For "Student Name" for example, I chose "Short Answer" [Figure 31].

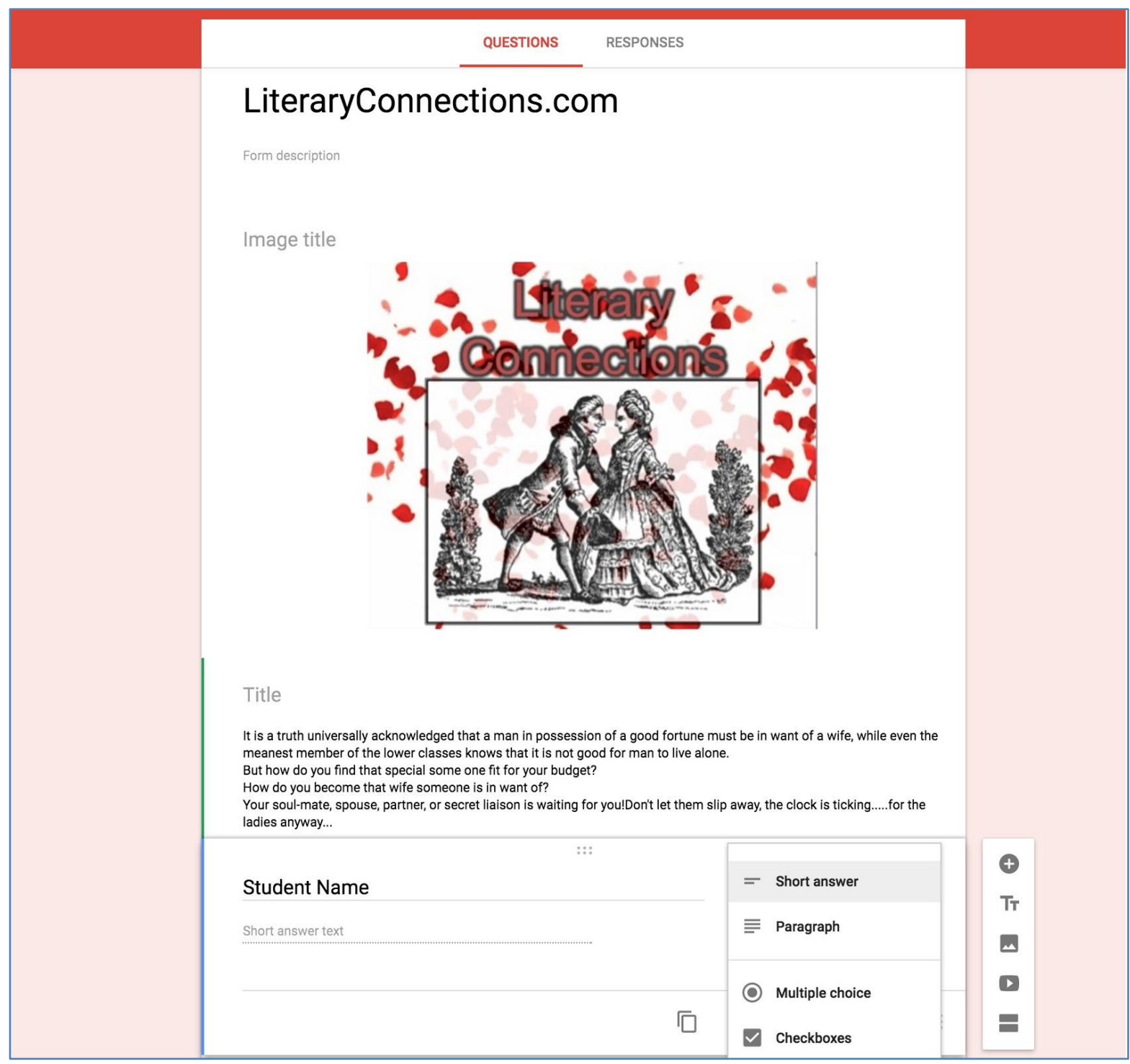

Figure 31: Entering a Question and Selecting Question Type 
To add more questions, simply click the plus sign icon to the right of a section, and select which question type you want to add. For this project I used a combination of multiple choice, short answer, and long answer options.

I sent a link to the site to my students who were also obliged to send me a picture of the character via email. You can see the final form by typing in LiteraryConnections.tumblr.com or by following this link. Once students completed filling out the forms, I had a database generated from their responses [Figure 32]. You can see a copy of the database, with student names removed, here.

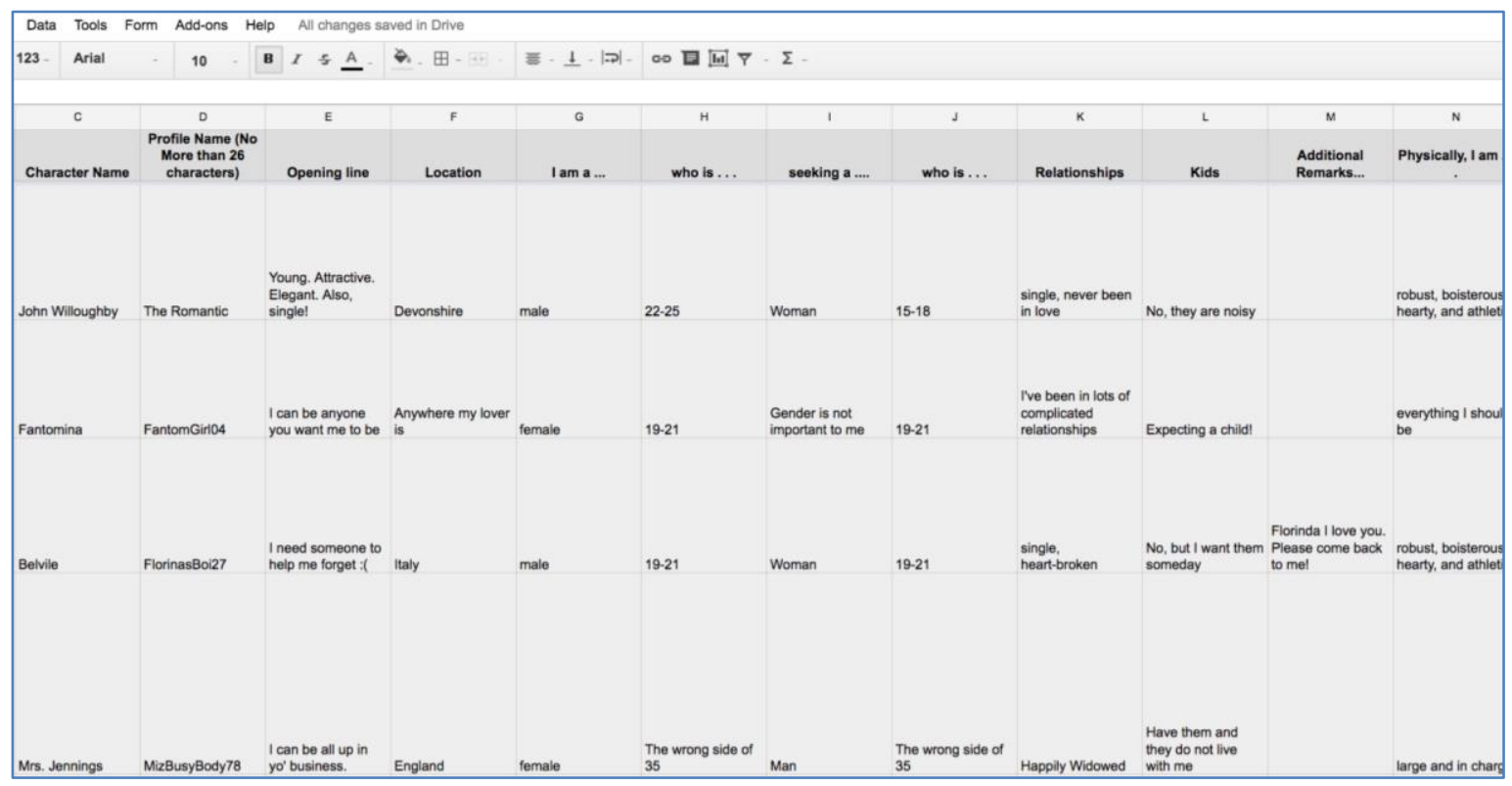

Figure 32: Google Forms Database

\section{Setting up the Tumblr}

In many ways, the rest of the process mirrors the steps of "Arabella's Valentines," except for students to get the online dating experience of browsing through profiles, a student worker and I copied and pasted all of the answers from the database into a PowerPoint template, creating a text box for each response given except for character name and student name. We then saved each profile and uploaded it to the Tumblr titled LiteraryConnections.tumblr.com. I also created a title post with an introduction to the assignment much as I did for "Arabella's Valentines" [Figure 33]. 


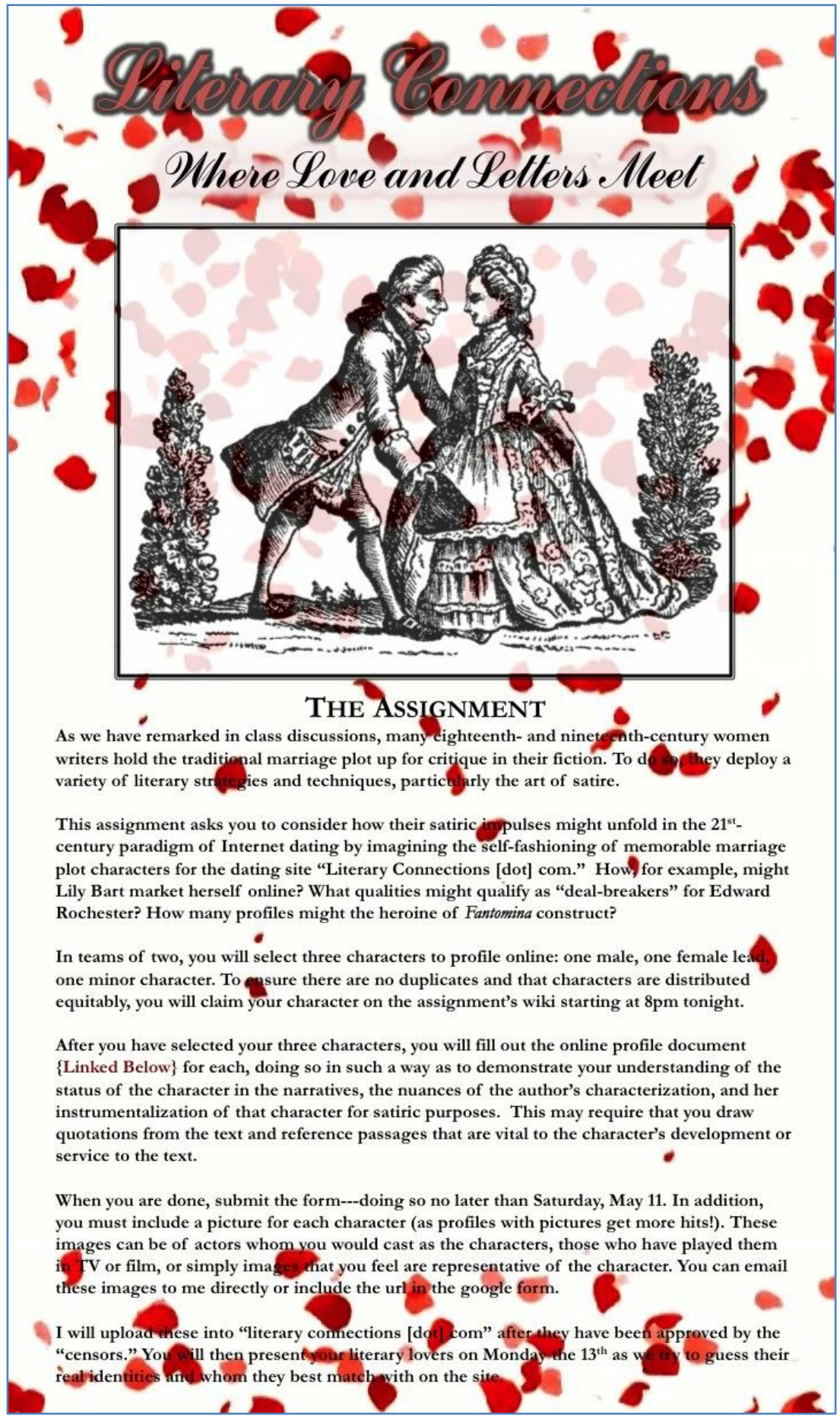

Figure 33: Title Page Blog Post for LiteraryConnections.tumblr.com 